\title{
Role of Traffic Emission on Temporal and Spatial Characteristics of Pollutant Concentration on Urban Road Network: A Case of Beijing
}

\author{
Zirui Wang, ${ }^{1}$ Huixin Zhou, ${ }^{1}$ Yang Si $\mathbb{D},{ }^{1}$ and Yahui $\mathrm{Li} \mathbb{D}^{2}$ \\ ${ }^{1}$ School of Transportation Science and Engineering, Beihang University, Beijing 100191, China \\ ${ }^{2}$ Institute of Transportation Development Strategy \& Planning of Sichuan Province, Chengdu 610041, China \\ Correspondence should be addressed to Yang Si; siyang@buaa.edu.cn and Yahui Li; 383269162@qq.com
}

Received 26 June 2020; Revised 3 October 2020; Accepted 24 October 2020; Published 21 November 2020

Academic Editor: Ronghui Zhang

Copyright (c) 2020 Zirui Wang et al. This is an open access article distributed under the Creative Commons Attribution License, which permits unrestricted use, distribution, and reproduction in any medium, provided the original work is properly cited.

\begin{abstract}
This research aims to calculate $\mathrm{PM}_{2.5}$ concentration on the road network by considering the network-wide traffic status, which can be used to support research about the impact of urban road network pollution concentration on health. The increase in the use and number of vehicles has brought about a large amount of vehicle exhaust emissions and increased urban air pollutants. This is also one of the important reasons why this issue is worth studying. In this research, traffic emission was an estimate based on networkwide traffic status which was calculated from vehicle trajectories and spatial variance-covariance matrix. An identification method of external input pollutants is proposed to determine the occurrence of external pollutants imported into the urban area. To calculate the impact of multiple influencing factors on the pollution concentration of the entire road network, a multivariate linear model was adopted to calculate a variety of influencing factors and calibrate the model parameters by collecting real data. The results show that traffic emissions, external input pollution, and wind impact are the main factors affecting the $\mathrm{PM}_{2.5}$ concentration on urban road networks. Combined with real-time traffic data, we can obtain the temporal and spatial characteristics of the pollutant concentration of the road network. For policymakers, our research can provide a method for calculating the $\mathrm{PM}_{2.5}$ concentration on the road network, which is useful for establishing a health assessment framework in the future.
\end{abstract}

\section{Introduction}

Ambient air pollution is a major factor for various diseases and cardiovascular health effect, which has been proven in epidemiological studies in the past decade, especially cardiorespiratory diseases [1-4]. Other studies have indicated that air pollution may be an important factor in autism in children [5]. The World Health Organization estimates that ambient air pollution caused approximately 3.7 million premature deaths every year [6]. In cities, $\mathrm{PM}_{2.5}$ from trafficrelated emissions has a nonnegligible impact on environmental pollution. With urbanization in many developing countries, motorization is also an inevitable trend. At the end of 2019, the number of private vehicles in Beijing was 4.974 million. Ten years ago, this number was only 3.19 million. In ten years, 1.784 million vehicles have been added and will continue to increase in the future [7]. The increased vehicle usage significantly contributes to urban air pollution. According to data released by the Beijing Municipal Bureau of Ecology and Environment in 2018, among the current local $\mathrm{PM}_{2.5}$ sources, mobile sources account for the largest proportion, reaching $45 \%$. Based on two facts, such as the increase in traffic emissions and the proximity of most pollution sources to homes or workplaces, many studies have highlighted traffic-related air pollution [8]. Therefore, obtaining an accurate road network pollution concentration value helps to assess the health impact of pollution on residents.

In recent years, the issues of vehicle emission and urban air pollution received more attention. One method to investigate the impact of traffic emission is to derive emission inventories, which can estimate the total traffic emission in 
regional [9, 10] or global [11]. Emission inventory can provide macroemission information about urban vehicles. Land-use regression (LUR) modeling approaches have gained more application in many cities in China [12, 13], Europe [14, 15], and North America [16-18]. Although it is a reasonable and reliably modeling approach, a standard LUR model still has a limitation that is not transferable to other areas or different scales. Such as areas with special terrain conditions such as the Swiss Alps [19]. And due to it is a macroscopic emission estimate, the resolution of the pollutant concentration will be limited. Pollution models can help traffic managers to control the traffic emission by selecting the most adequate management strategy [20]. The main input of models is traffic data and meteorological data $[9,21-25]$. Some studies are only based on traffic data $[22,26]$ or meteorological data [27]. Fan et al. [28] collected field emission data, and they are incorporated into the microscopic traffic simulation tool for quantifying the emissions. González-Aparicio et al. [29] presented three different linear regression models: simple linear regression, linear regression with interaction terms, and linear regression with interaction terms following Sawa's Bayesian information criteria to describe the dependence of $\mathrm{PM}_{10}$ concentration on traffic, meteorological, and temporal data. However, when calculating traffic emissions, more attention needs to be paid to the dynamic variability of traffic. As we all know, urban traffic is a huge and complex system, and its biggest feature is constant change. Vehicles keep moving on the road. Only using the total number of vehicles in the city to calculate traffic emissions, it is impossible to get the difference in emissions between different roads at a certain time. Therefore, it is necessary to consider the traffic status when calculating traffic emissions. When we introduce the traffic status, we need more and more detailed traffic-related data and consider the temporal and spatial changes in traffic status, which makes the problem more complicated. In some previous studies, fixed measurements were used to describe air pollution exposure in specific areas [19, 30-32]. Sun et al [24] found that the length of the road, the distance to the city center, and the density of bus stations would substantially increase the emission rate. However, only using these measurements cannot adequately represent local traffic-related air pollution which shows high spatial variability on a small scale. Although it is currently possible to directly measure traffic pollution through measurement equipment, it is impossible to directly measure urban pollution. Since the city contains a large number of roads, it is very costly to install measurement equipment on all roads, so it is impossible to install measurement equipment on all roads. Therefore, using traffic data and a small amount of pollutant monitoring point data is an achievable and necessary way to estimate the level of road pollution in the city. Since the traffic status is constantly changing, the precise traffic data of the entire network are not available. More other forms of data need to be combined for further research. Not only do pollutants on urban road networks include traffic emissions, but pollutants present in the background environment also can affect the concentration of pollutants on urban road networks. Therefore, the study of the concentration of pollutants in the urban road network needs to explore the spatial and temporal relationship between traffic conditions and environmental changes.

This study proposes a framework to estimate the spatiotemporal $\mathrm{PM}_{2.5}$ concentration on the urban road network. A spatial variance-covariance matrix was used to calculate the travel time of the entire road network by some real-time traffic data. Vehicle trajectory data and spatial variance-covariance matrix are used to calculate the travel statues (travel time, traffic volume, speed, and acceleration of vehicle) on the road network. The external input pollutant identification method is used to obtain the period of no external pollutant input. A case study near the Beijing Olympic Sports Center revealed the influence of different factors on the pollution concentration of the road network and calibrated the parameters of the model. Then, the model was applied to the Beijing road network within the Fourth Ring Road, and the $\mathrm{PM}_{2.5}$ concentration changes of the road network during the morning rush peak-hour period in Beijing were analyzed.

The main methodological contributions in this study are as follows:

(a) An emission model that considers the state of traffic is applied to the road network. It provides a practical method to calculate traffic-related $\mathrm{PM}_{2.5}$ emissions on the road network.

(b) An external input pollutant identification method is established through existing monitoring points. When external pollutants enter or leave, information such as the location of the pollutant input or departure, the time of input or departure, and the movement direction of the pollutant can be obtained.

(c) When estimating the $\mathrm{PM}_{2.5}$ concentration on the road network, this study uses actual data to verify the emission model parameters. And we combine the characteristics of meteorological conditions and external input pollution. As a result, the spatialtemporal pollution concentration of road network can be estimated.

By considering dynamic traffic conditions, the study provides a method for estimating $\mathrm{PM}_{2.5}$ concentration on urban road networks. The temporal and spatial characteristics of road network pollution can be obtained. $\mathrm{PM}_{2.5}$ concentration on the road network concentration is of great significance for future environmental pollution supervision and the establishment of the health assessment framework.

The paper is organized as follows. Section 2 describes the estimation method of travel time on the road network and traffic emissions. And the multiple linear regression model is used to evaluate the concentration of the road network. A method for identifying regional input pollutants is proposed. Section 3 contains background environmental pollution data, meteorological data, and data of pollution imported outside Beijing. In Section 4, the actual pollution data of the road network are used to calibrate the parameters of the model, and the importance of various factors is shown. Then, the model is applied to the entire road network. The results 
of the study are summed up and conclusions are drawn in Section 5 .

\section{Methodology}

2.1. Estimation of Travel Time on the Road Network. Traffic emission is also an important part of the pollutant concentration on the road network [33]. To estimate the traffic emissions of the urban road network, the traffic status on the road network needs to be obtained first. However, the traffic data of the entire road network are unavailable, so the traffic status on the road network cannot be directly obtained. This study uses a method based on the spatial variance-covariance relationship of travel time on arterial road networks to estimate traffic status of road networks. A simple road network example is shown in Figure 1.

Suppose links 1, 2, and 3 of the road network have their own set of historical travel time: $\left\{t_{11}, t_{12}, \ldots, t_{1 n}\right\}$, $\left\{t_{21}, t_{22}, \ldots, t_{2 n}\right\}$, and $\left\{t_{31}, t_{32}, \ldots, t_{3 n}\right\}$, where $t_{1 n}, t_{2 n}$, and $t_{3 n}$ are the travel time on links 1,2 , and 3 at a particular time $n$, respectively. The $3 \times 3$ matrix is the spatial variance-covariance matrix of the link travel times at a particular time for the three-link network case:

$$
K=\left[\begin{array}{lll}
K_{11} & K_{12} & K_{13} \\
K_{21} & K_{22} & K_{23} \\
K_{31} & K_{32} & K_{33}
\end{array}\right] .
$$

$K_{i i}=\operatorname{Var}\left(t_{1}\right)$, the variance of the link travel time $\left\{t_{i 1}, t_{i 2}, \ldots, t_{i n}\right\}$, where $i=1,2$, and 3 .

$K_{i j}=\operatorname{Cov}\left(t_{i}, t_{j}\right)$, the covariance of the link travel time for $\left\{t_{i 1}, t_{i 2}, \ldots, t_{i n}\right\}$ and $\left\{t_{j 1}, t_{j 2}, \ldots, t_{j n}\right\}$, where $i, j=1,2$, and 3 , and $i \neq j$.

The travel time on each link that varies with other links in the network is indicated by the travel time covariance. When the travel time of one link increases and leads to the increase of travel time on other links, the value of the corresponding position in the matrix is positive. The negative covariance indicates that when the travel time on one link increases, the travel time of another link would decrease. For example, $K_{13}$ should be negative because links 1 and 3 are the two alternative routes.

The traffic time on an upstream link is directly affected by the traffic condition on a downstream link. That is why the spatial covariance relationships of travel times are important for travel time estimation in congested urban road networks. A more detailed description of the method can be found in [34]. The travel time on arterial roads without realtime data can be indirectly deduced by equation (1):

$$
T_{e}=\bar{T}_{e}+K_{21} K_{11}^{-1}\left(T_{d}-\bar{T}_{d}\right) .
$$

$T_{e}=$ travel time estimate on the arterial road without real-time data.

$T_{d}=$ travel time estimate on the arterial road with realtime data.

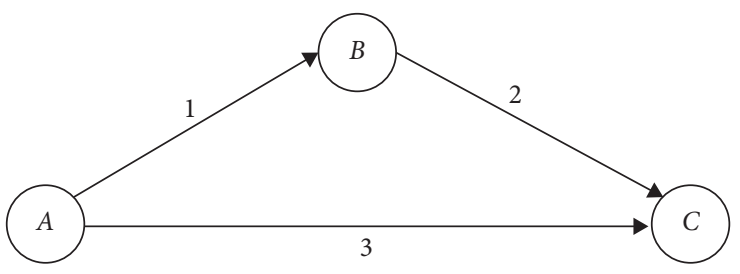

Figure 1: A simple network case.

$\bar{T}_{e}=$ average travel times in the historical database without respect to the arterial road

$\bar{T}_{d}=$ average travel times in the historical database concerning the arterial road

$K_{11}=$ real-time updated variance of the travel times corresponding to the arterial road with real-time data.

$K_{21}=$ real-time updated travel time covariance of the arterial road without and with real-time data.

The k-nearest neighbor (k-NN) method was also adopted to calibrate the spatial variance-covariance matrix of link travel times for the real-time estimation. The k-NN method was based on similar past cases which were referred to as the nearest neighborhood. We take the travel time of all links which one link connected as the input. And we look for similar situations in the historical database to get the current travel time.

The procedure for the $\mathrm{k}-\mathrm{NN}$ method is described as follows:

(1) Identify the variables of one road and the value of $k$

(2) Input all states of variables into the database

(3) Calculate Euclidean distance of a new state to each state in the database

(4) Choose output of $k$-nearest neighborhood

(5) Average the output of $k$-nearest neighborhood

Through this method, we can get the traffic time on the road network.

2.2. Estimation of Traffic Emissions. After obtaining the traffic status of the road network, traffic-related emissions can be calculated. Traffic and vehicle emission linkage (TRAVEL) model was used in this study, which was proposed by Yang et al. [35]. The model takes traffic flow and vehicle running bins (VRBs) as input to obtain traffic emissions. The date, acceleration, speed, location, and other parameters of the car driving are recorded by the GPS device. The traffic flow data were calculated by the method discussed above and calibrated with official statistics based on the National Bureau of Statistics and peer-reviewed publications [21]. Two-stage mapping is included in the TRAVEL model. The first stage is mapping from traffic flow patterns to vehicle running bins (VRBs). We use 39 traffic flow patterns and the corresponding emission rates proposed by Yang et al. [35] in our study. Traffic patterns are determined based on the vehicle speed and traffic flow. A bottom-up approach was 
used in the second mapping to aggregate emission rates of $\mathrm{VRB}$ to basic emission rates (BERs, $\mathrm{g} / \mathrm{km}$ ) of the corresponding flow pattern and estimate the emission factor (EF, in $\mathrm{g} / \mathrm{km}$ ) in the target traffic pattern. We use equation (3) to convert the unit of emission factor in combination with the vehicle velocity:

$$
\mathrm{EF}\left(\frac{g}{s}\right)=\frac{\mathrm{EF}(\mathrm{g} / \mathrm{km}) \times 3600}{V(\mathrm{~km} / \mathrm{h})} .
$$

The emission control level of automobiles is a key factor in determining emission factors. The emission control strategies in China followed European control policies. Generally, China III, China IV, and China V are equivalent to the Euro II, Euro III, and Euro IV standards, respectively. More attention has been paid to vehicle emissions in recent years. In 2019, Beijing has completely banned vehicles of China III enter the Sixth Ring Road. Trucks matching the criteria of China IV and China V can only enter the Sixth Ring Road between 0am and 6am. We used the emission factors generated by the TRAVEL model. The total emissions are calculated as follows:

$$
E_{T}=\sum_{t} \sum_{i} \sum_{j} \mathrm{VTT}_{t, i} \times P_{j} \times \mathrm{EF}_{t, i, j}
$$

where the subscripts $t, i$, and $j$ stand for a time in a typical day, road category, and car category, respectively; $\mathrm{VTT}_{t, i}$ represents the vehicle traveled time of the entire fleet on road $i$ at time $t$ in a typical day. In this research, $\mathrm{VTT}_{t, i}$ was calculated by the traffic speed and statistical data on the road $i$ at time $t$. $E_{T}$ represents the total emission. $P_{j}$ represents the penetration rate of emission control level $j$ in the entire fleet. The emission control level of vehicles was determined by the implementation year of the emission control standard and the year when the vehicle was registered.

2.3. Multivariate Regression Model. The multivariate linear regression model was used to compare different types of variables and to assess the strength of the correlation between factors that lead to changes in the concentration of pollutants on the road:

$$
P_{t}=\alpha_{t} A_{t}+B_{t}+\beta_{t},
$$

where $P_{t}$ denotes the concentration of $\mathrm{PM}_{2.5}$ on the road during hour $t$, and $\alpha_{t}$ is the coefficient describing the influence of factor $A_{t}$ on hourly pollutant concentration. The factors assessed included different hours of the day, temperature, relative humidity, wind power, wind direction, atmospheric pressure, hourly rainfall, working days or nonworking days, and hourly traffic emissions. The time accuracy of the above data is converted to hours. The wind direction factor was divided into eight directions: north (337.5-22.5 $)$, northwest $\left(292.5-337.5^{\circ}\right)$, west $\left(247.5-292.5^{\circ}\right)$, southwest $\left(202.5-247.5^{\circ}\right)$, south $\left(157.5-202.5^{\circ}\right)$, southeast $\left(112.5-157.5^{\circ}\right)$, east $\left(67.5-112.5^{\circ}\right)$, and northeast $\left(22.5-67.5^{\circ}\right)$. The data of wind direction were obtained in continuous numerical form.
However, when the wind direction in degrees is used as an explanatory variable, a similar wind direction will bring a huge difference. For example, 1 and 359 are close to the north wind, but the value is very different. Therefore, eight categories with 45 intervals (north, northwest, west, southwest, south, southeast, east, and northeast) are used instead of continuous wind direction. $B_{t}$ represents the random intercept at time $t$ which is used to capture potential variations that are not explained by $A_{t}$, for example, changes caused by secondary pollution in the environment. $\beta_{t}$ represents residual random normal error. A positive coefficient indicates that pollutant concentration increases with the increase of the corresponding factor units. Parameters that describe the spatial variation are also included in multivariate linear regression models, such as traffic flow on the road network and external input pollution. They combine temporally variables such as traffic counts or traffic emission, and meteorological and temporal parameters in this study. Backward and forward step-by-step selection procedures are used (covariates are selected at a significance level of 0.1 ) to select the final model. After excluding models with physically impractical estimates, a 10-fold cross-validation method was used to validate the model [36].

\subsection{External Input Pollutant Identification Method.} According to data released by the Beijing Municipal Bureau of Ecology and Environment in 2018, of all $\mathrm{PM}_{2.5}$ pollution in Beijing, external transmission accounts for one-third of the total. It is necessary to identify the external input pollution, so we need to establish a method to identify external input pollution. We use some of the current monitoring points to establish an internal monitoring zone and an external monitoring zone. Two pollution monitoring zones are shown in Figure 2. The composition of the monitoring zone can be found in Table 1 .

When pollutants arrive or leave the monitoring point, the concentration of the monitoring point will suddenly rise or fall. We define this situation as an abnormal concentration of pollutants (ACPs). According to this phenomenon, we can identify the pollutant input in temporal and spatial perspectives.

In the temporal dimension, we set a threshold for the changes in pollution data at each monitoring point.

When the pollutant concentration at the monitoring point has an ACP situation at a certain moment, it is considered that there is a pollutant entering or leaving at this moment. From the spatial dimension, we set a different threshold for the pollutant concentration of each monitoring point in the same monitoring zone. When, at a certain moment, the pollutant concentration difference between a certain monitoring point and other monitoring points in the same monitoring zone exceeds the threshold, we believe that at that moment, foreign matter input pollutants pass or leave the monitoring point. We use this method to identify whether there is an external pollutant input, and we can get the external pollutant input or the time of leaving, which is very helpful for our follow-up research. 


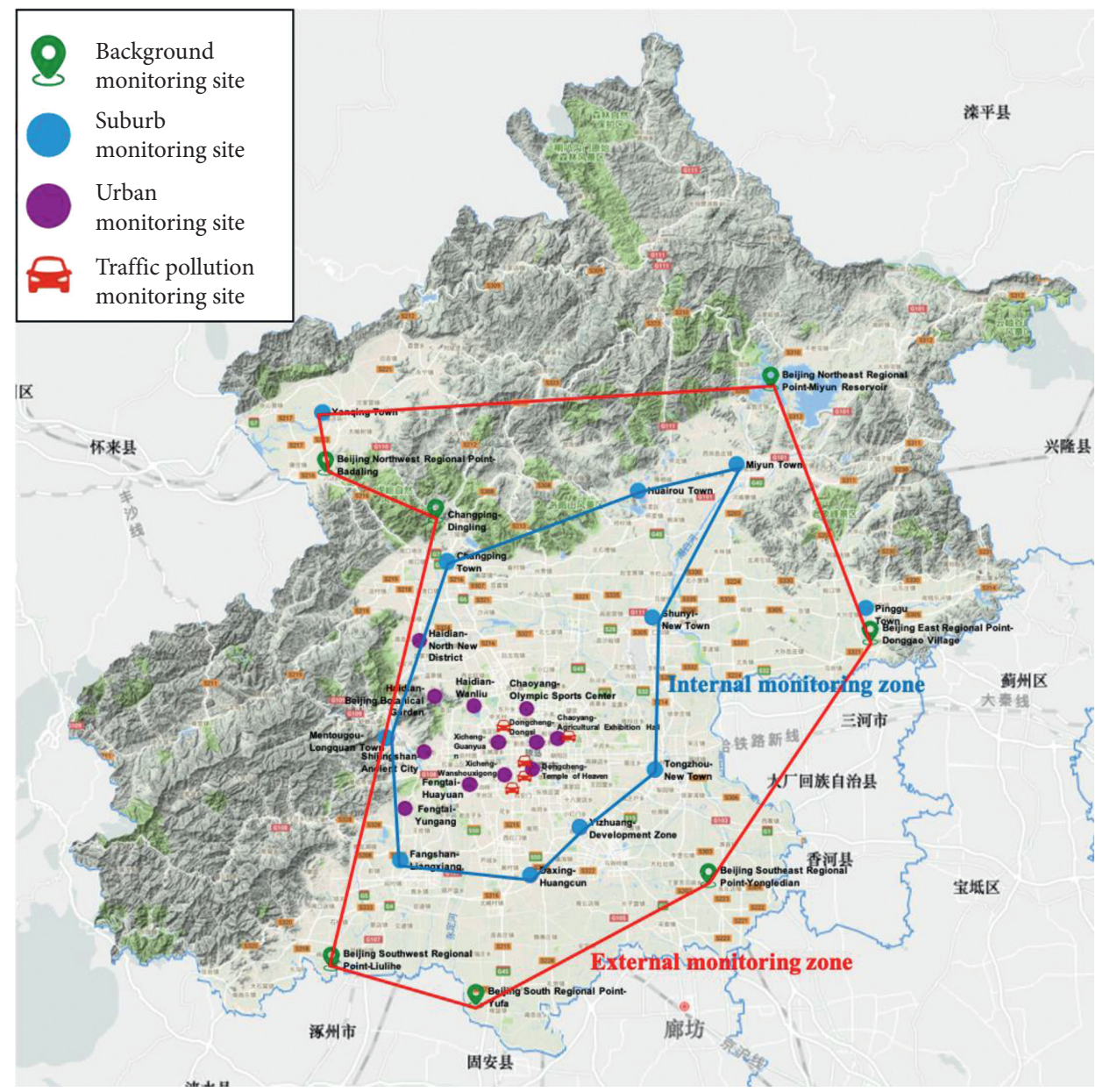

FIGURE 2: The composition of the external input pollutant monitoring zone.

TABLE 1: External pollutant identification system.

Monitoring site type

Internal monitoring zone sites

External monitoring zone sites
Name of monitoring site

Fangshan-Liangxiang, Daxing-Huangcun, Yizhuang-Development Zone, Tongzhou-New Town, Shunyi-New Town, Changping-Town, Mentougou-Longquan Town, Huairou-Town, Miyun-Town

Changping-Dingling, Yanqing-Town, Beijing Northwest Regional Point-Badaling, Beijing Northeast Regional Point-Miyun Reservoir, Beijing East Regional Point-Donggao Village, Beijing Southeast Regional PointYongledian, Beijing South Regional Point-Yufa, Beijing Southwest Regional Point-Liulihe

\section{Data Collection and Analysis}

Beijing, the capital of China, is the economic and cultural center of China. Beijing is situated at the northwest border of the North China Plain $\left(115.7^{\circ}-117.4^{\circ} \mathrm{E}, 39.4^{\circ}-41.6^{\circ} \mathrm{N}\right)$. There are 16 districts belong to Beijing. Among them, Xicheng District, Dongcheng District, Haidian District, Chaoyang District, Fengtai District, and Shijingshan District are urban areas. The remaining areas are suburbs. The total land area of Beijing is 16410.54 square kilometers. The mountainous area of Beijing is 10,200 square kilometers, accounting for $62 \%$ of the total area, and the plain area is 6,200 square kilometers, accounting for $38 \%$ of the total area, as shown in Figure 3. The mountainous areas are distributed in the west, north, and northeast of Beijing. The terrain of Beijing is high in the northwest and low in the southeast. The average altitude of
Beijing is 43.5 meters, the elevation of the plain is 20 to 60 meters, and the mountainous area is usually 1000 to 1500 meters above sea level. The arterial roads in Beijing are radially distributed, such as the Second Ring Road, Third Ring Road, and Fourth Ring Road from the central city to the suburbs (Figure 4). This means that the urban road system in Beijing is also radial and is constantly expanding to support the increasing traffic volume. At the end of 2019, the permanent population was approximately 21.536 million [21]. The residential population in Beijing's Sixth Ring Road accounts for $78 \%$ of the city's total population [7]. The number of vehicles in Beijing has increased year by year in the past ten years. As of 2019, the total number of cars in Beijing is 6.08 million, of which 4.89 million are private vehicles. The structure of the road systems, in conjunction with the large number of vehicles traveling in the city, 


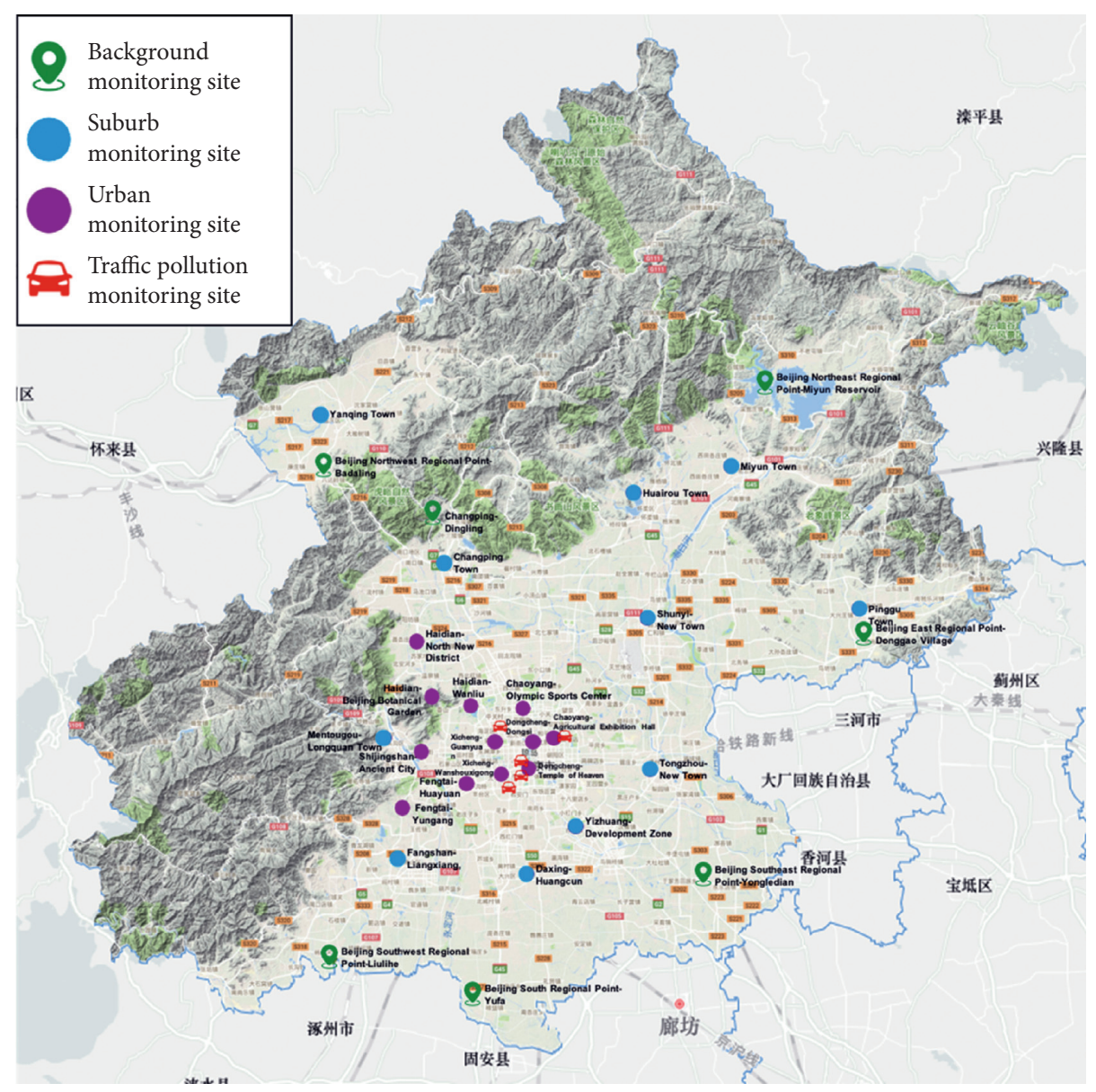

Figure 3: Distribution of 35 monitoring sites in Beijing.

produces significant congestion, and this leads to increased exhaust emissions.

3.1. Environmental Pollution Data. The pollution data used in this study were collected by the Beijing Municipal Bureau of Ecology and Environment. They shared data from 35 monitoring sites, and each monitoring site can measure data of six monomers, $\mathrm{PM}_{2.5}, \mathrm{PM}_{10}, \mathrm{CO}, \mathrm{NO}_{2}, \mathrm{SO}_{2}$, and $\mathrm{O}_{3}$. The distribution of monitoring sites covers all 16 administrative regions of Beijing. The locations of 35 monitoring sites in Beijing are given in Figure 3.

According to the different locations of the monitoring sites, all monitoring sites are divided into four types, namely, background monitoring sites, suburb monitoring sites, urban monitoring sites, and traffic pollution monitoring sites. The background monitoring sites are the green point in Figure 3. Background monitoring sites are located in the outermost periphery of Beijing and far away from urban areas. The consideration of this arrangement is to avoid the impact of human life and factory production on the monitoring data. The surrounding environment of the background monitoring sites is stable, which is suitable as a benchmark for other kinds of monitoring sites. Dodge blue monitoring sites are suburban monitoring sites. Suburban monitoring sites are used to monitor the air pollution of ten suburb districts in Beijing.
The suburbs have a smaller density of population than the urban areas, which means fewer traffic emissions from car emissions and living-related air pollution of residents. The urban pollution monitoring sites are located in the purple position in Figure 3. The urban monitoring sites are responsible for monitoring the pollution situation in Beijing, where more than 10 million people work and live in the urban area (Beijing Bureau of Statistics, 2019) [21]. The red car sign in the picture represents the location of the traffic pollution monitoring sites, which are distributed close to the road. The specific names and types of monitoring sites are shown in Table 2 According to the requirements of the "Beijing ThreeYear Action Plan to Win the Blue-Sky Defense Warfare" in 2018, Beijing divides air quality into six levels according to the concentration of the pollutant $\mathrm{PM}_{2.5}$, as shown in Table 3 .

For instance, Figure 5 shows the concentration of $\mathrm{PM}_{2.5}$ at the Olympic Sports Center monitoring site for 8760 hours in 2019. Through the line chart, we can find that there was extremely heavy pollution in January 2019, and the value of $\mathrm{PM}_{2.5}$ concentration exceeded $500 \mu \mathrm{g} / \mathrm{m}^{3}$. At this monitoring point, the cumulative duration of extreme pollution in 2019 was about 10 hours. The most serious external input pollution that occurred in January lasted about $0.1 \%$ of the entire year.

Through the pie chart (Figure 6), we found that the cumulative hours of level 1 accounted for $68.8 \%$ of 2019 . General weather accounts for $21.1 \%$ of the total hours. We 


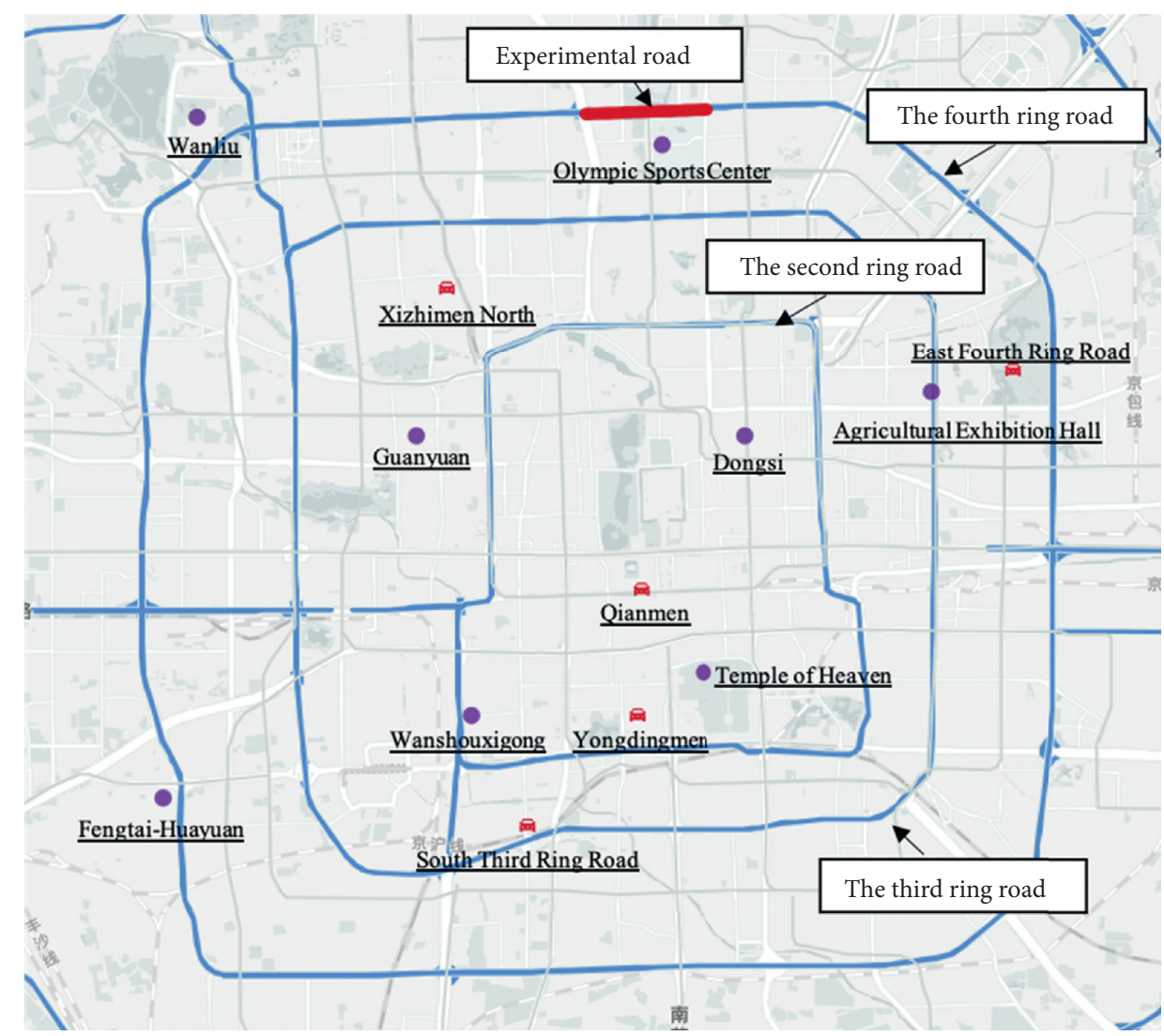

Figure 4: Distribution of monitoring sites in the Fifth Ring Road of Beijing.

TABLE 2: Classification of air quality monitoring sites in Beijing.

Monitoring site type

Background monitoring sites

Suburb monitoring sites (11)

Urban monitoring sites (12)

Traffic pollution monitoring sites (5)
Name of the monitoring site

Changping-Dingling, Beijing Northwest Regional Point-Badaling, Beijing Northeast Regional PointMiyun Reservoir, Beijing East Regional Point-Donggao Village, Beijing Southeast Regional PointYongledian, Beijing South Regional Point-Yufa, Beijing Southwest Regional Point-Liulihe Fangshan-Liangxiang, Daxing-Huangcun, Yizhuang-Development Zone, Tongzhou-New Town, ShunyiNew Town, Changping-Town, Mentougou-Longquan Town, Pinggu-Town, Huairou-Town, MiyunTown, Yanqing-Town

Dongcheng-Dongsi, Dongcheng-Temple of Heaven, Xicheng-Guanyuan, Xicheng-Wanshouxigong, Chaoyang-Olympic Sports Center, Chaoyang-Agricultural Exhibition Hall, Haidian-Wanliu, HaidianNorth New District, Haidian-Beijing Botanical Garden, Fengtai-Huayuan, Fengtai-Yungang, ShijingshanAncient City

Qianmen, Yongdingmen, Xizhimen North, South Third Ring Road, East Fourth Ring Road
TABle 3: Pollution classification according to $\mathrm{PM}_{2.5}$ concentration.

\begin{tabular}{lcc}
\hline Level & Air quality & Pollution value range \\
\hline Level 1 & Excellent & $0-50$ \\
Level 2 & Good & $51-100$ \\
Level 3 & Light pollution & $101-150$ \\
Level 4 & Moderate pollution & $151-200$ \\
Level 5 & Severe pollution & $201-300$ \\
Level 6 & Extreme pollution & $>300$ \\
\hline
\end{tabular}

also found that the hours of light pollution (pollution concentration greater than level 3) accounted for $8.1 \%$ of the total hours.
Figure 7 shows the $\mathrm{PM}_{2.5}$ concentration distribution at different time scales at the Olympic Sports Center monitoring site. The result shows that the $\mathrm{PM}_{2.5}$ pollutant value in winter months (December, January, and February) is higher than that in summer months (June, July, and August). In January, there was heavy pollution imported from other regions. By dividing the data according to the day of the week, it is found that the daily pollution situation is more average, but it is prone to abnormal heavy pollution on nonworking days. Looking at 24 hours of a day, the median pollutants in peak hours are slightly higher than those in evening peak hours. And there are also higher median pollutants in the early morning hours, which are higher than those in early peak hours. 


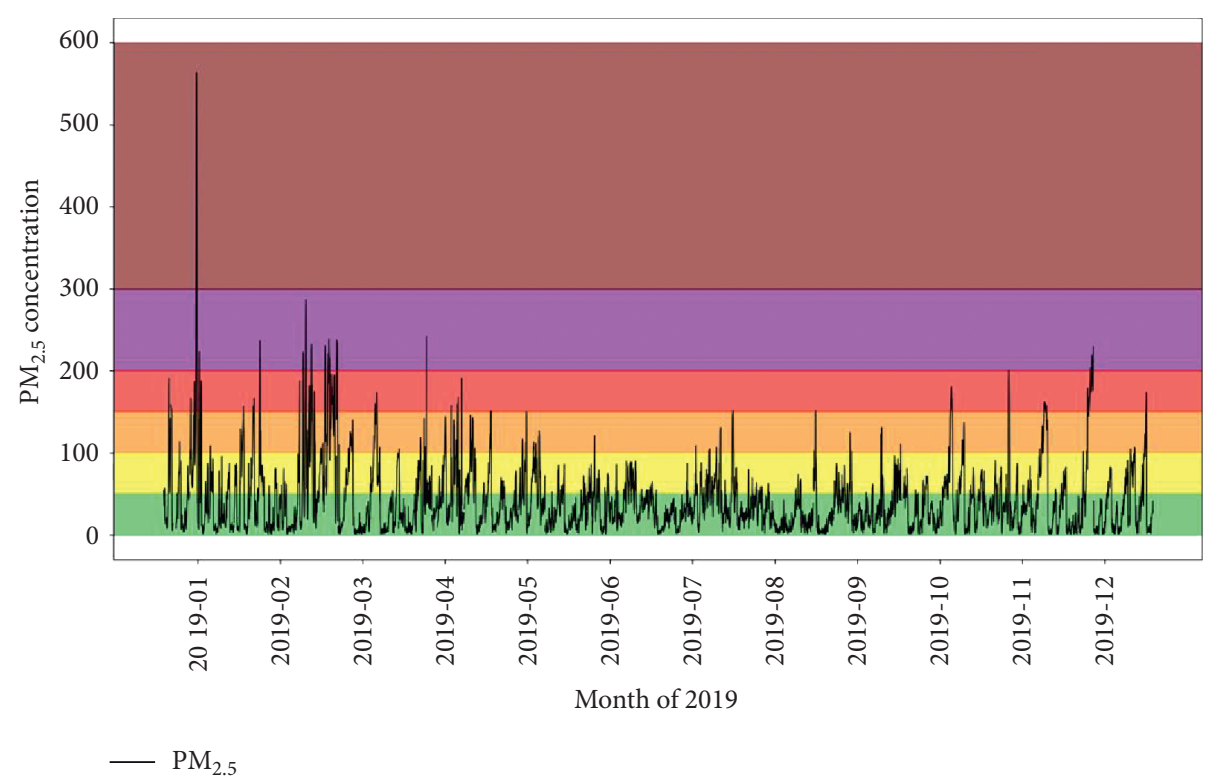

Figure 5: The concentration of $\mathrm{PM}_{2.5}$ at the Olympic Sports Center monitoring site in 2019.

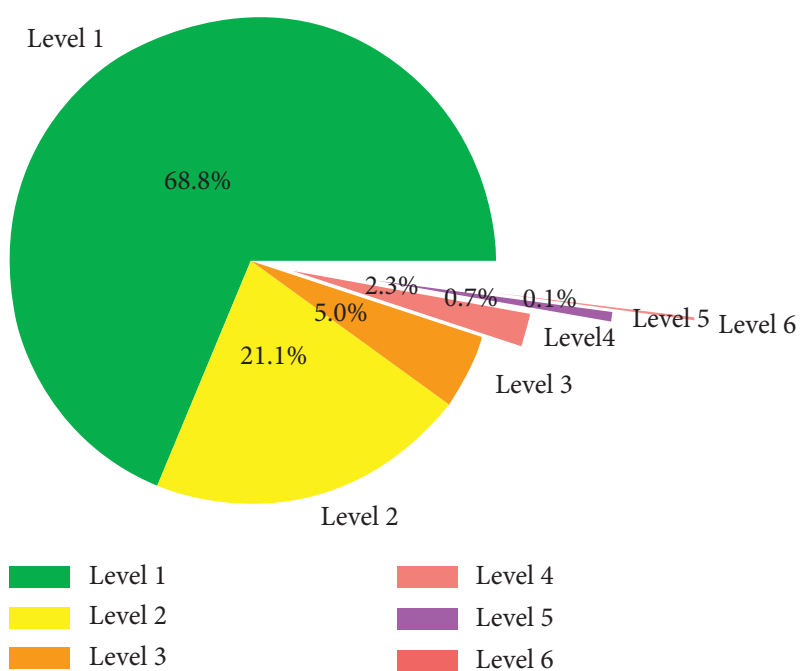

FIgURE 6: Proportion of pollution level classification.

3.2. Meteorological Data. The meteorological data of Beijing were provided by the Beijing Meteorological Bureau. The meteorological data set contains hourly air temperature, wind speed, wind direction, relative humidity, and atmospheric pressure. To match the weather data with the traffic data and the monitoring sites data, the time granularity of the meteorological data we obtain is also hourly. The climate of Beijing is typical of a semihumid continental monsoon climate in the northern temperate zone, with high temperature and rain in summer and cold and dry season in winter. Spring and autumn are shorter than summer and winter. The north wind prevails in Beijing in winter, and the east and southeast winds prevail in summer. However, the northern and western parts of Beijing are surrounded by mountains, as shown in Figure 3, and north and west winds are rare in Beijing.
The rank of wind speed is shown in Table 4. According to the wind speed, the hourly wind speed is ranked.

Histograms (Figures 8 and 9) show that all wind direction data are compared with the number of hours of different wind directions and wind levels. Figure 7 shows the hourly distribution of wind direction in Beijing for 12 months in 2019. It can be found that the number of hours of southwest wind and northeast wind is the largest in the whole year. Figure 10 shows the distribution of collected temperature, atmospheric pressure, and relative humidity data of 2019. The obvious change in temperature is the main characteristic of temperate climate. July is the hottest month in Beijing, the highest temperature is 37.8 degrees Celsius, the lowest temperature is 19.4 degrees Celsius, and the median temperature in July is 27.9 degrees Celsius. And the coldest month is December. The minimum temperature in December is - 14.3 degrees Celsius.

Atmospheric pressure decreases with increasing temperature, so July is the season with the lowest atmospheric pressure in Beijing. The lowest pressure in July is $990 \mathrm{hPa}$, the highest atmospheric pressure is $1008 \mathrm{hPa}$, and the median atmospheric pressure is $999.53 \mathrm{hPa}$. The median atmospheric pressure in the highest month is about 26 higher than the median atmospheric pressure in the lowest month. The maximum relative humidity value of each month in 2019 is relatively close, within the range of 89-96 percent. The minimum relative humidity in the summer and autumn months is significantly higher than that in winter and spring months, which is also consistent with the climate characteristics of Beijing. The highest relative humidity that appeared in July is about $62.65 \%$.

3.3. Identification of External Contaminants. When external pollutants are imported into Beijing, the pollutants will drift away with the wind. It can be found from multiple monitoring points along the wind direction that the concentration 


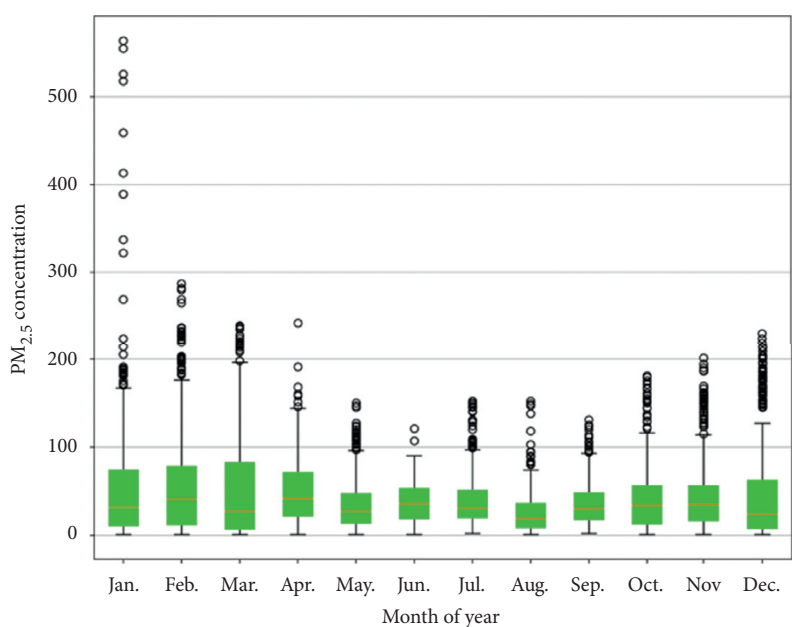

(a)

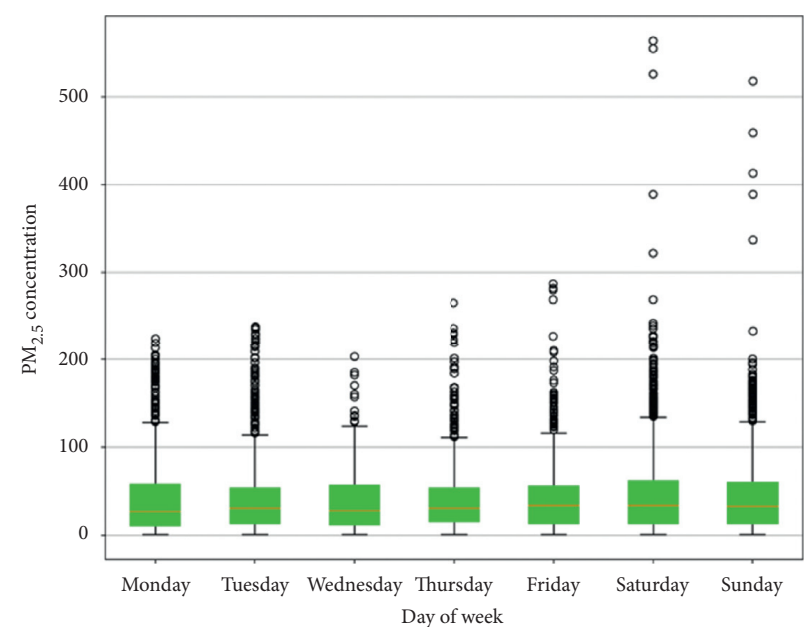

(b)

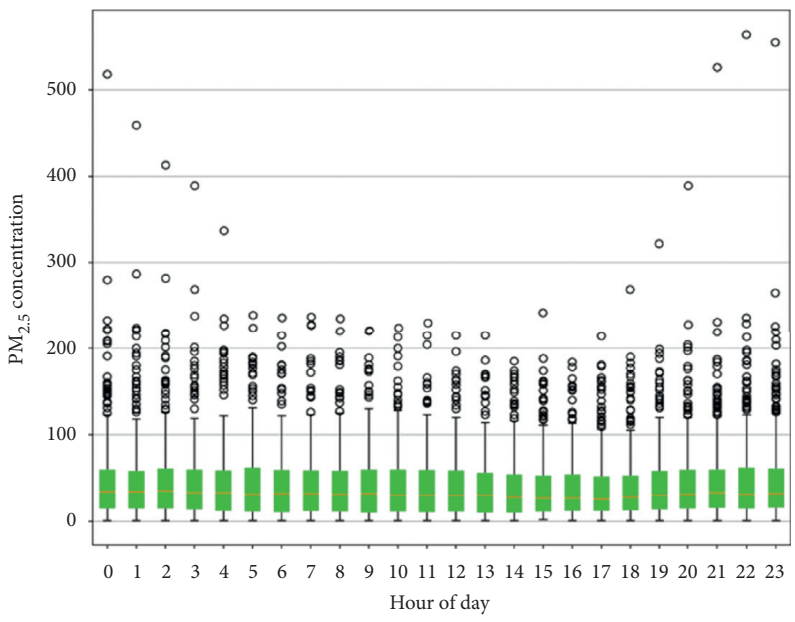

(c)

FIgure 7: Comparison of $\mathrm{PM}_{2.5}$ concentration at the Olympic Sports Center monitoring site under different time scales.

TABLE 4: Wind level classification according to wind speed.

\begin{tabular}{lccc}
\hline Wind speed level & Actual wind speed $(\mathrm{m} / \mathrm{s})$ & Wind speed level & Actual wind speed $(\mathrm{m} / \mathrm{s})$ \\
\hline 0 & $0.0-0.2$ & 7 & $13.9-17.1$ \\
1 & $0.3-1.5$ & 8 & $17.2-20.7$ \\
2 & $1.6-3.3$ & 9 & $20.8-24.4$ \\
3 & $3.4-5.4$ & 10 & $24.5-28.4$ \\
4 & $5.5-7.9$ & 11 & $28.5-32.6$ \\
5 & $8.0-10.7$ & 12 & $32.7-36.9$ \\
6 & $10.8-13.8$ & 13 & $37.0-41.4$ \\
\hline
\end{tabular}

of pollutants gradually increases from the upwind direction to the downwind direction. Figure 11 shows the external pollutants' input from the southwest in January.

On January $12^{\text {th }}$, the $\mathrm{PM}_{2.5}$ concentration at the Liulihe background pollutant monitoring site which is the most southwestern site of Beijing rises first. The highest concentration of $\mathrm{PM}_{2.5}$ even exceeds $600 \mu \mathrm{g} / \mathrm{m}^{3}$. Due to the wind direction at that moment in Beijing was southwest, the pollutants drift along the wind direction from the southwest to the northeast. As can be seen from the location distribution of the monitoring sites in
Figure 11, from the Liulihe background monitoring site to the northeast, there are Fangshan monitoring site, Fengtai Garden monitoring site, Guanyuan monitoring site, Olympic Sports Center monitoring site, etc. The order of increasing the concentration of $\mathrm{PM}_{2.5}$ in Figure 11 just confirms the conjecture that pollutants will spread with the wind.

Through the above methods, we use background monitoring sites and suburban monitoring sites as identification sites to determine whether there are external pollutant inputs. When the concentration of pollutants at all 


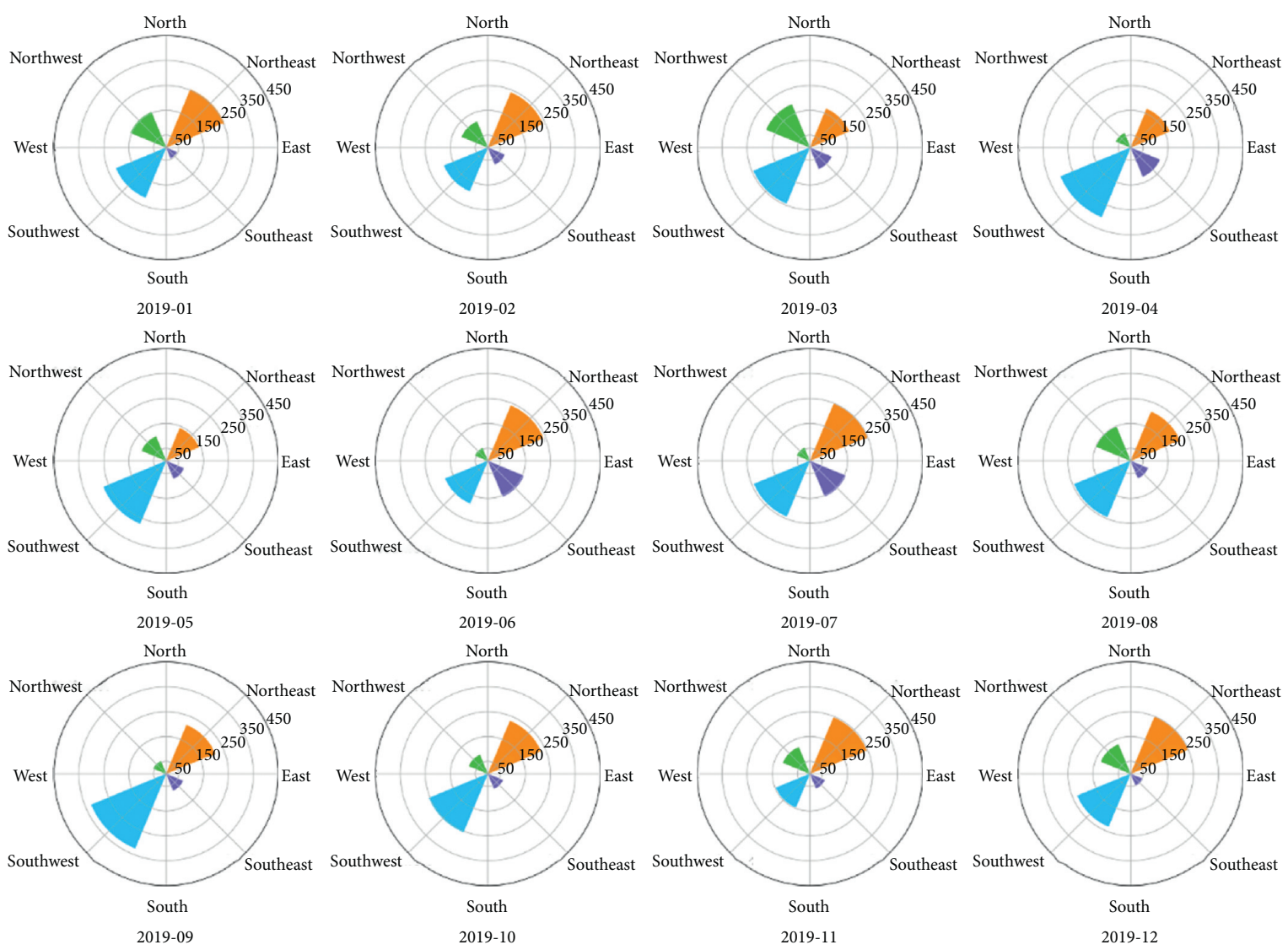

FIGURE 8: Comparison of the number of hours with different wind directions in the months of 2019.

identification sites does not rise abnormally, we assume that no external pollution enters the central city within this period. The data sources used in the text are summarized in Table 5.

\section{Case Study}

4.1. Parameter Calibration. To calibrate the parameters of the emission model, we measured and calculated the $\mathrm{PM}_{2.5}$ concentration of the section between the Fourth Ring Jianxiang Bridge and Anhui Bridge by placing monitoring equipment. The monitoring device is placed on the lamp at the side of the road. The entire measurement process meets China's ambient air quality standards (GB 3095-2012). The time range of data collection is from August $7^{\text {th }}$ to August $11^{\text {th }}$. Use the external input pollutant identification method to exclude the data of the period with pollutant input to correct the emission model. The concentration of pollutants on urban road networks is much higher than the concentration monitored by the regional monitoring sites, and similar results have appeared in the study [37].

4.1.1. Statistical Analysis of Data. The GPS data were filtered to calculate the travel speed from the Jianxiang Bridge to Anhui Bridge. As shown in Figure 12, the green shaded area is the Olympic Sports Center, a large forest park in Beijing. The Jianxiang Bridge and Anhui Bridge are two overpasses on the Fourth Ring Road, respectively, on the west and east sides of the Olympic Sports Center. The length of the road between the two overpasses is approximately 2.5 kilometers. The Olympic Sports Center monitoring site is located inside the Olympic Sports Center. The experimental road monitoring site we set is on the Fourth Ring Road between the Jianxiang Bridge and Anhui Bridge. The location of this road segment can be found in Figure 4 .

The $\mathrm{PM}_{2.5}$ concentration of the Olympic Sports Center monitoring site in August is shown in Figure 13. An external $\mathrm{PM}_{2.5}$ pollution input occurred on August $26^{\text {th }}$, causing the concentration of pollutants to be light pollution level.

The measurement of $\mathrm{PM}, \mathrm{NO}, \mathrm{NO}_{\mathrm{x}}$, black carbon, and polycyclic aromatic hydrocarbons (PAHs) on the highway was taken by Westerdahl et al. [38]. Fruin et al. showed that the pollutants are highly correlated with traffic-related emissions [39]. Similar correlations were shown in the research by mobile sites for measurements done within $400 \mathrm{~m}$ of a highway [31]. Seasonal factors may also be one of the related factors. We assume that externally input pollutants will pass through at least one background monitoring site. The identification of external input pollutants has been introduced in the previous section.

Table 6 presents a statistic of the measured air pollutants and meteorological parameters at the Olympic Sports Center monitoring site and traffic flow of the experimental road. To avoid interference caused by other months, only the data of August 2019 are considered. According to national 

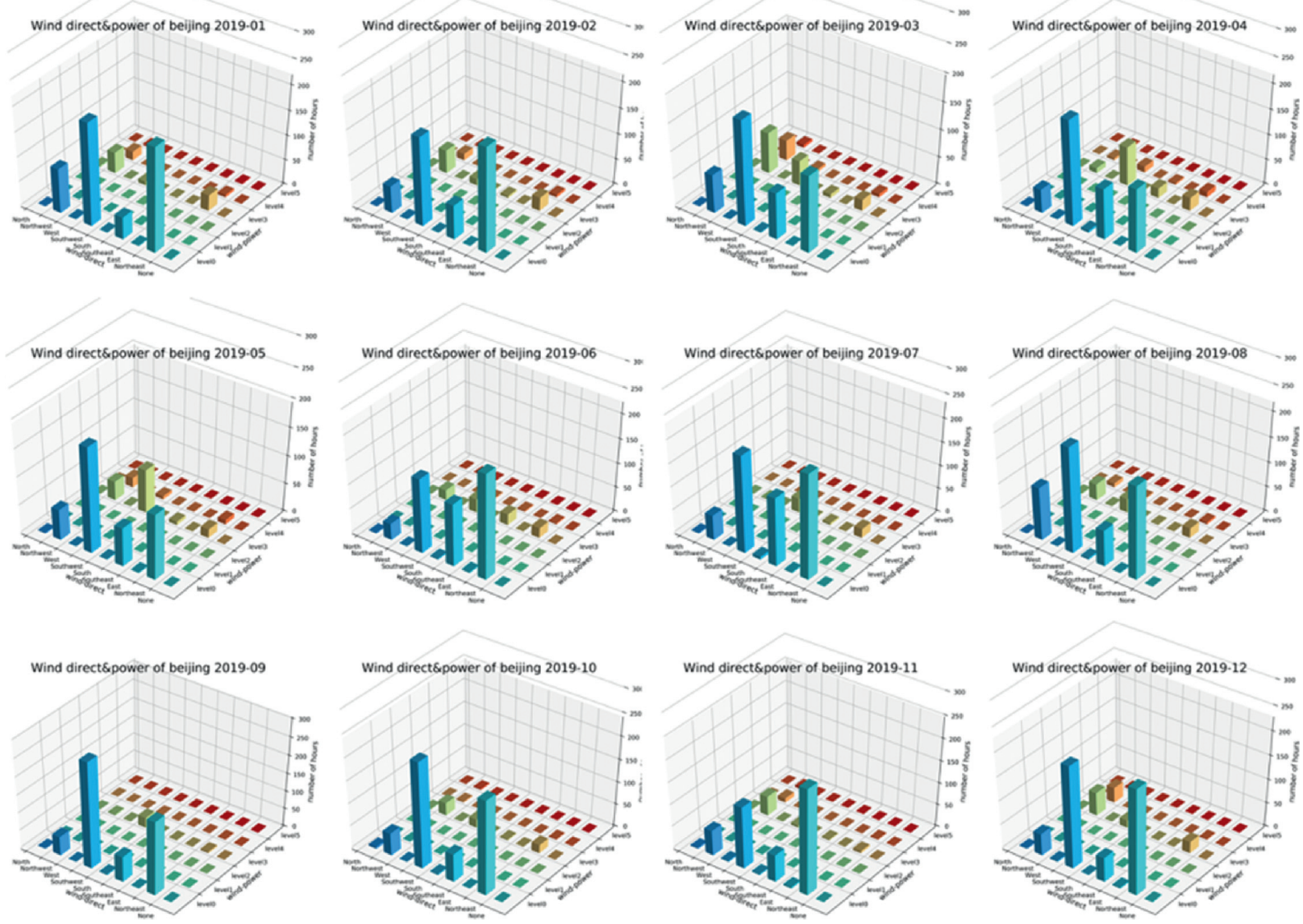

Figure 9: Comparison of the number of hours with different wind levels in different months of 2019.

standards [40], the annual average of $\mathrm{PM}_{2.5}$ and $\mathrm{PM}_{10}$ should not exceed $35 \mu \mathrm{g} / \mathrm{m}^{3}$ and $70 \mu \mathrm{g} / \mathrm{m}^{3}$, the annual $\mathrm{SO}_{2}$ should not exceed $70 \mu \mathrm{g} / \mathrm{m}^{3}$, and the annual average value of $\mathrm{NO}_{2}$ should not exceed $40 \mu \mathrm{g} / \mathrm{m}^{3}$. The average hourly concentration of CO cannot exceed $10 \mu \mathrm{g} / \mathrm{m}^{3}$, and average hourly concentration of $\mathrm{O}_{3}$ cannot exceed $200 \mu \mathrm{g} / \mathrm{m}^{3}$ After statistical analysis, the data from the monitoring sites of the Olympic Sports Center in August are in full compliance with national standards.

\subsubsection{Traffic Emission of the Experimental Road Section.} When calculating the travel speed of the research section, we not only considered the mean value of speed but also included the variance value of speed into the calculation. If only considering the mean value of speed, the dispersibility of speed may be masked. There may be such a situation that the difference between the maximum value and the minimum value of the speed is large, but after taking the average value, it is close to the mean value which the speed fluctuation range is small. Therefore, the variance value of the speed needs to be included in the calculation, which can effectively distinguish the above situation.

Figure 14 shows the result of the average speed on the experimental road section in August, which was calculated using GPS data and the method discussed in Section 2.1. The red line represents the average speed on working days, while the blue line represents the speed on nonworking days. According to the regulations of the Beijing Municipal Traffic Management Department, the maximum speed of the Fourth Ring Road is $80 \mathrm{~km} / \mathrm{h}$, so this is the reason why the maximum value of the average speed in Figure 14 is around $80 \mathrm{~km} / \mathrm{h}$. In the curve of working days, there are two processes in which the travel speed has dropped significantly and then increased. The first decrease starts at $6 \mathrm{am}$ and reaches the lowest value between $8 \mathrm{am}$ and $9 \mathrm{am}$. The minimum value of travel speed drops below $20 \mathrm{~km} / \mathrm{h}$. After reaching the lowest value, travel speeds begin to increase and stabilize at $11 \mathrm{am}$. The second significant decrease in the travel speed starts at around $5 \mathrm{pm}$ and reaches the minimum value around $7 \mathrm{pm}$. The minimum travel speed is about 25 $\mathrm{km} / \mathrm{h}$. Then, the travel speed gradually increased again and stabilized at $10 \mathrm{pm}$. The travel speed rises to the limit value at $1 \mathrm{am}$, and it can be inferred that the number of vehicles on the road has decreased significantly after this time. The vehicle may travel at the maximum speed restricted by the road without obstruction.

It can be speculated that the traffic conditions of the Fourth Ring Road are affected by commuting. During commuting hours, the Fourth Ring Road becomes congested. Due to the implementation of flexible punch time in Beijing, we can see that the travel speed starts to recover 


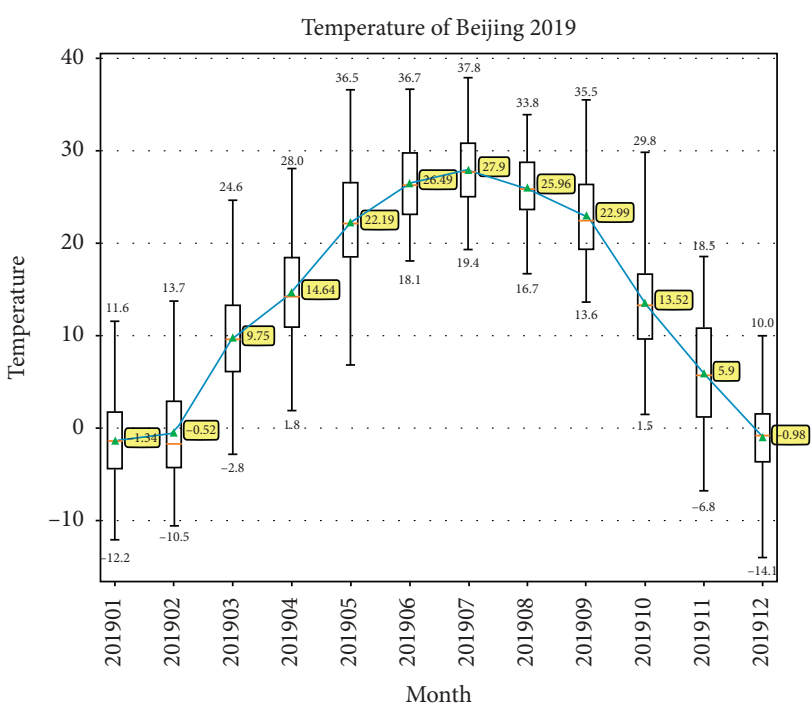

(a)

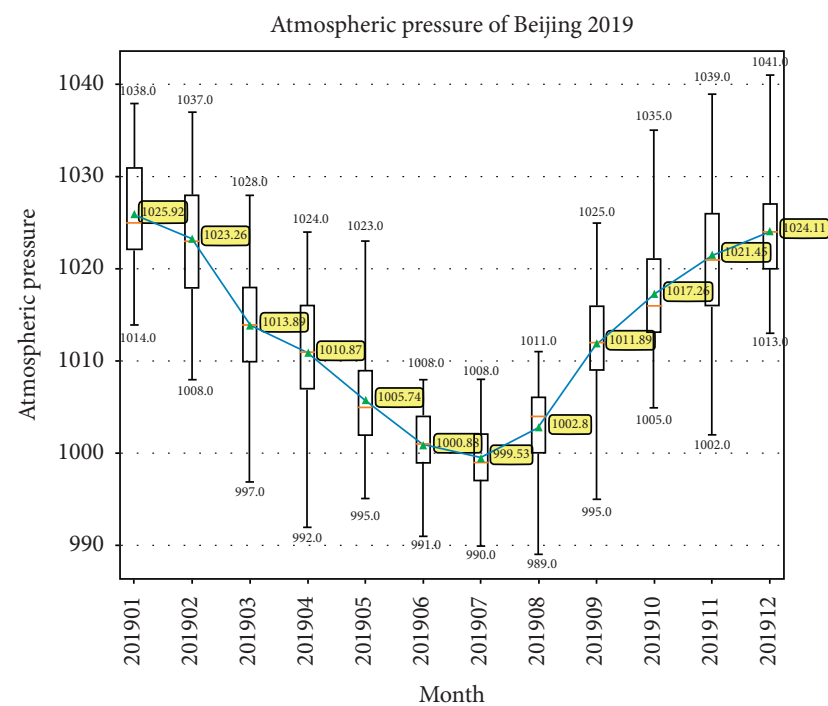

(b)

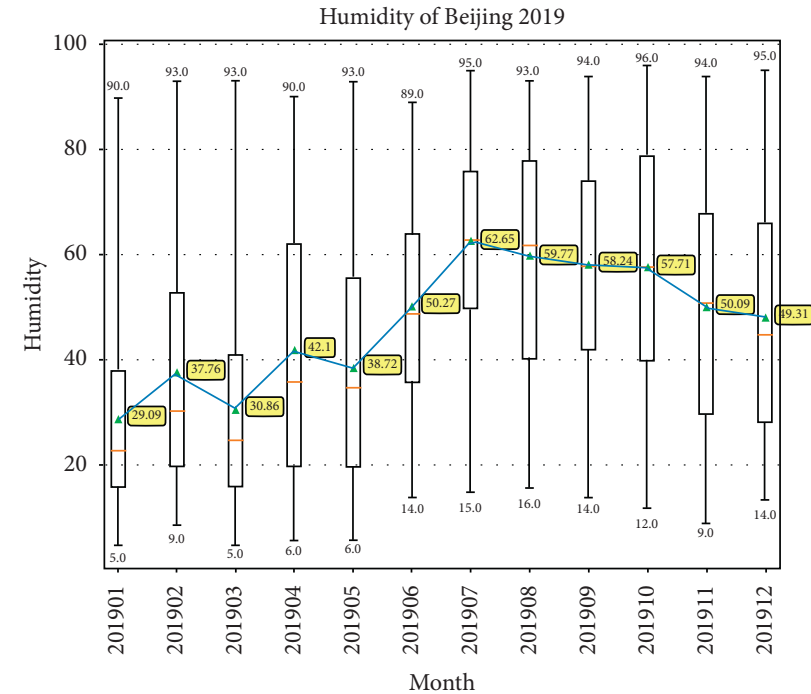

(c)

Figure 10: Distribution of air temperature, atmospheric pressure, and relative humidity.

before 9am and returns to a stable level at $11 \mathrm{am}$. Similarly, most companies are off duty at $5 \mathrm{pm}$, so the travel speed starts to decrease at $5 \mathrm{pm}$. The minimum value of travel speed in the morning rush hour is lower than that in the evening rush hours. Based on this, we can infer that the traffic condition during morning rush hours may be more congested than that during evening rush hours. Since there is no commuting traffic demand on nonworking days, two peaks of congestion like working days do not exist in the blue curve. On nonworking days, the lowest travel speed of the experimental road section is around $50 \mathrm{~km} / \mathrm{h}$. We can know that the traffic conditions on nonworking days are better than those on working days. Comparing the two curves, it can be found that the time people travel by car on nonworking days is about an hour later than that on working days. This can be seen from the moment when the travel speed drops in the morning.
Using the method proposed in the previous section, combined with the travel speed and traffic flow (obtained through road monitors and camera videos), the traffic emissions on the experimental road section can be calculated. The shaded area in Figure 15 is the 95\% confidence interval. The estimated traffic emissions of the experimental sections on working days and nonworking days are shown in Figure 15. On working days, the lowest $\mathrm{PM}_{2.5}$ concentration of road vehicles throughout the day was at $5 \mathrm{am}$. After $5 \mathrm{am}$, the number of vehicles on the experimental road section begins to increase, so the traffic emission of the experimental road section increases too. The $\mathrm{PM}_{2.5}$ concentration of the experimental road section reaches the highest value at $9 \mathrm{am}$. The maximum concentration of $\mathrm{PM}_{2.5}$ exceeds $70 \mu \mathrm{g} / \mathrm{m}^{3}$. Between 11am and $5 \mathrm{pm}$, the $\mathrm{PM}_{2.5}$ concentration of road stabilizes at around $40 \mu \mathrm{g} / \mathrm{m}^{3}$. The $\mathrm{PM}_{2.5}$ concentration in the evening rush hour also exceeded $60 \mu \mathrm{g} / \mathrm{m}^{3}$, but it was still 


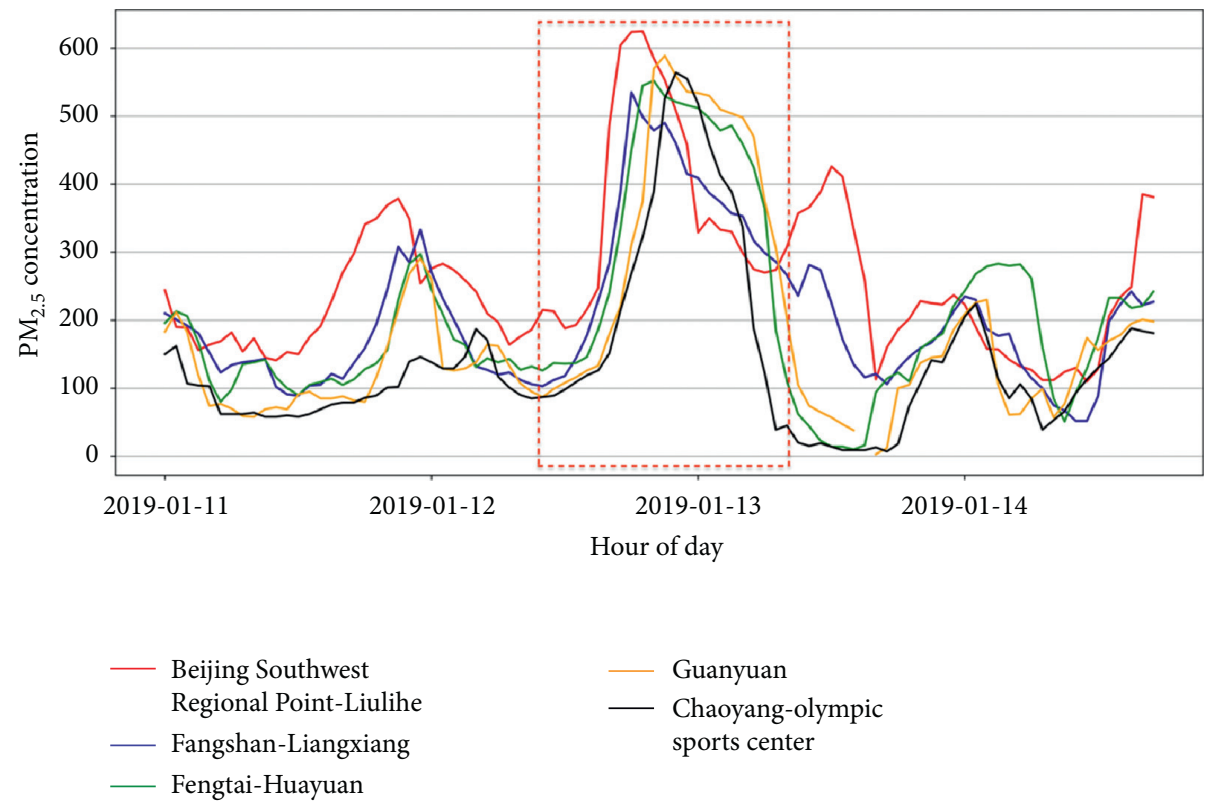

Figure 11: A case of external pollutant process from the southwest.

TABle 5: Data type and source.

\begin{tabular}{lc}
\hline Type of data & Data sources \\
\hline Meteorological data & Beijing Meteorological Bureau \\
Pollution data of urban monitoring sites & Beijing Municipal Bureau of Ecology and Environment \\
Vehicle GPS data & Beijing Taxi Company \\
\hline
\end{tabular}

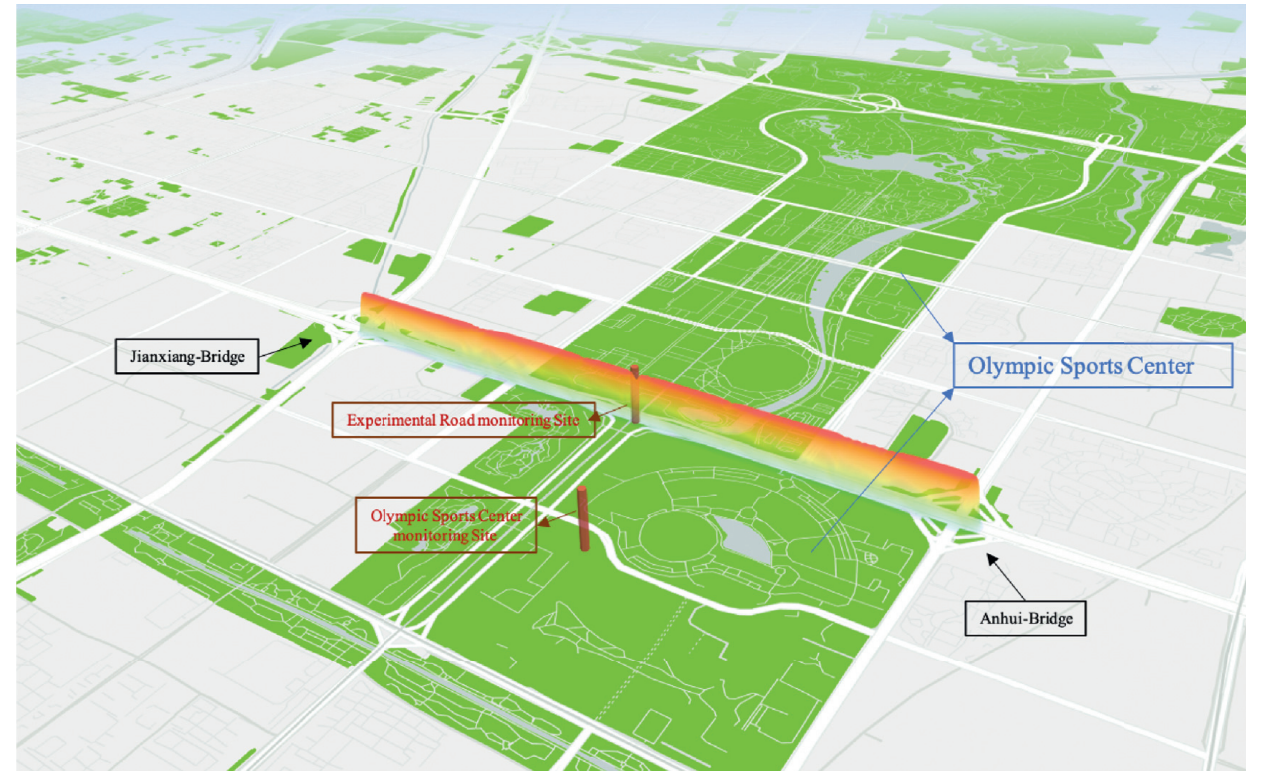

FIgURE 12: The location of experimental road, road monitoring site, and Olympic Sports Center monitoring site.

lower than the maximum concentration in the morning peak hours.

The $\mathrm{PM}_{2.5}$ concentration on nonworking days also starts to rise at $5 \mathrm{am}$, but it does not have an obvious peak like working days. In nonworking days, the pollutant concentration is almost stable at around $40 \mu \mathrm{g} / \mathrm{m}^{3}$. There is also a peak of traffic emission between $0 \mathrm{am}$ and $5 \mathrm{am}$. After our investigation at night, it was found that Beijing prohibited 


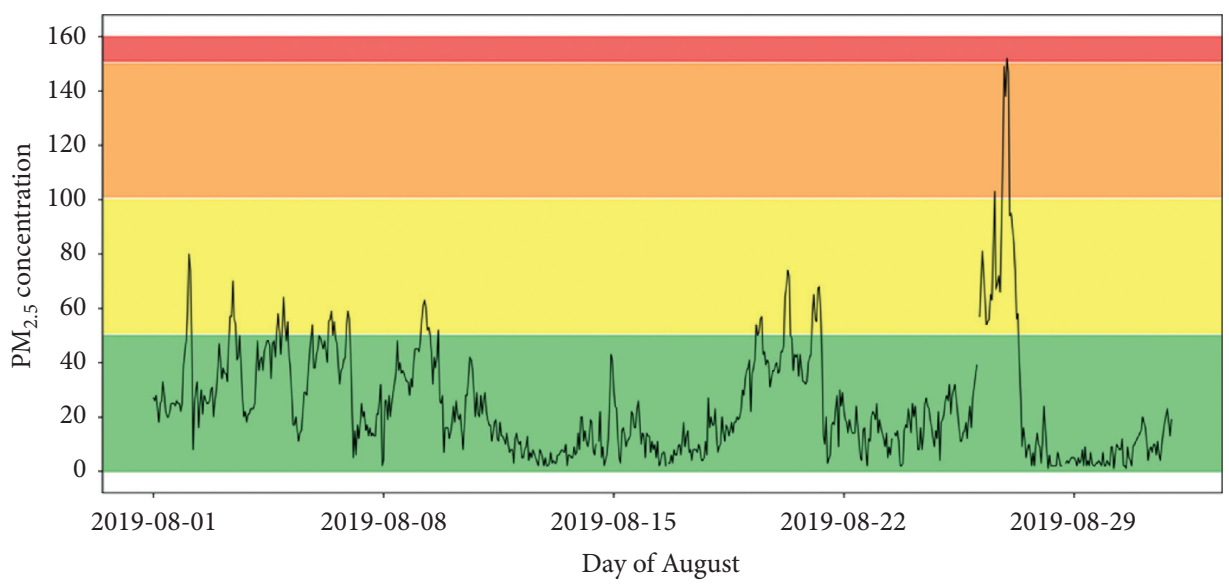

- $\mathrm{PM}_{2.5}$

Figure 13: The concentration of $\mathrm{PM}_{2.5}$ at the Olympic Sports Center monitoring site in August.

Table 6: The general summary statistics of Olympic Sports Center monitoring site in August 2019.

\begin{tabular}{|c|c|c|c|c|c|}
\hline & Mean & Std & Median & Min & Max \\
\hline \multicolumn{6}{|l|}{ Air pollutants } \\
\hline $\mathrm{PM}_{2.5}\left(\mu \mathrm{g} / \mathrm{m}^{3}\right)$ & 24.44 & 20.94 & 19 & 1 & 152 \\
\hline $\mathrm{PM}_{10}\left(\mu \mathrm{g} / \mathrm{m}^{3}\right)$ & 40.59 & 24.30 & 37 & 1 & 162 \\
\hline $\mathrm{SO}_{2}\left(\mu \mathrm{g} / \mathrm{m}^{3}\right)$ & 2.41 & 0.93 & 3 & 1 & 8 \\
\hline $\mathrm{NO}_{2}\left(\mu \mathrm{g} / \mathrm{m}^{3}\right)$ & 32.95 & 21.76 & 1 & 26 & 118 \\
\hline $\mathrm{CO}\left(\mathrm{mg} / \mathrm{m}^{3}\right)$ & 0.57 & 0.24 & 0.6 & 0.1 & 1.6 \\
\hline $\mathrm{O}_{3}\left(\mu \mathrm{g} / \mathrm{m}^{3}\right)$ & 69.62 & 51.66 & 1 & 64 & 213 \\
\hline \multicolumn{6}{|l|}{ Traffic counts } \\
\hline Average hourly traffic flow (working days) & 2513 & 2062.85 & 1608 & 243 & 14790 \\
\hline Average hourly traffic flow (nonworking days) & 1388 & 326.24 & & 223 & 3720 \\
\hline \multicolumn{6}{|l|}{ Meteorological data } \\
\hline Temperature $\left({ }^{\circ} \mathrm{C}\right)$ & 25.96 & 3.43 & 25.8 & 16.7 & 33.8 \\
\hline Relative humidity (\%) & 59.77 & 21.39 & 62 & 16 & 93 \\
\hline Atmospheric pressure $(\mathrm{Pa})$ & 1002.80 & 4.26 & 1004 & 989 & 1011 \\
\hline
\end{tabular}

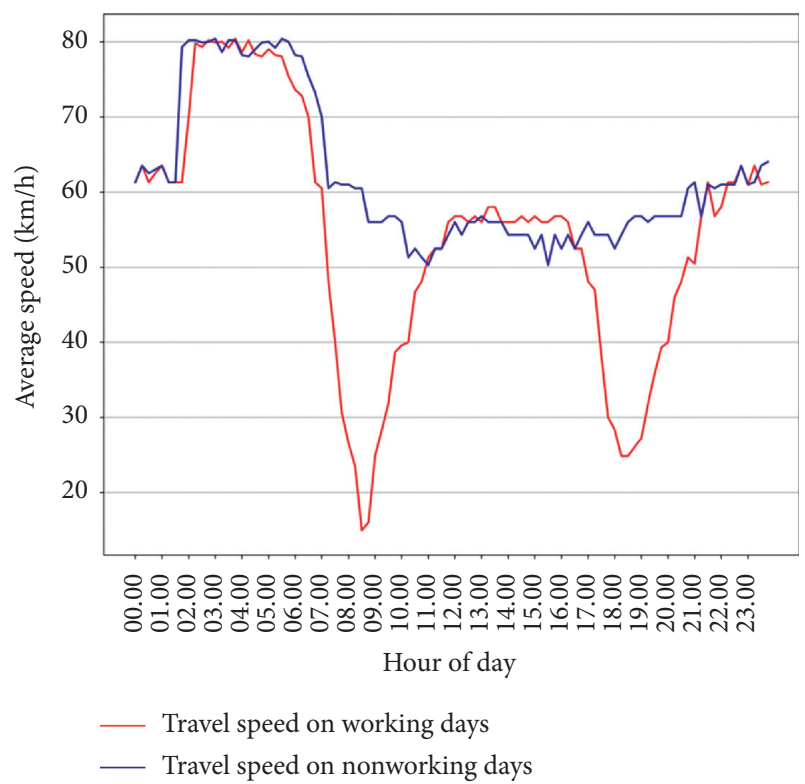

FIgURE 14: Travel speed of the experimental road section.

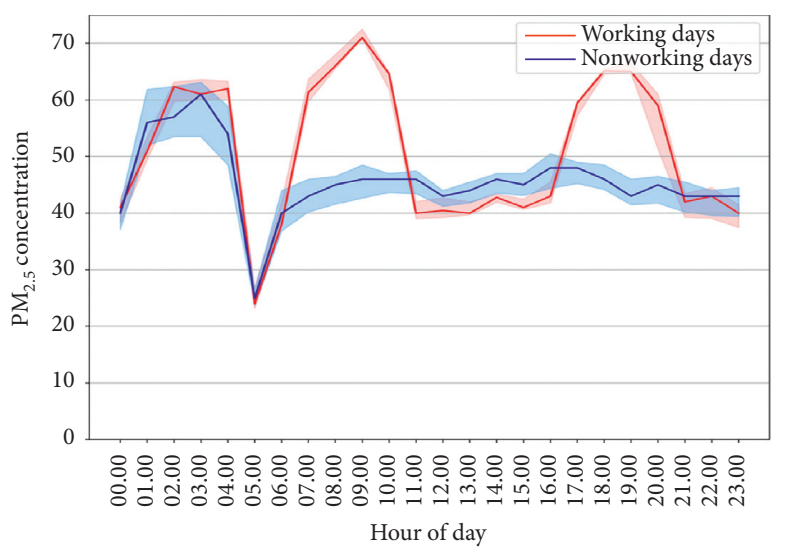

FIGURE 15: $\mathrm{PM}_{2.5}$ concentration of vehicle emissions on the Fourth Ring Road.

the trucks with an emission control level below China V to enter the Sixth Ring Road between 6am and $11 \mathrm{pm}$. Therefore, trucks below the emission control levels of the China V can only enter the Sixth Ring Road after 11 pm and 
leave before 6am. The supply of fresh vegetables, fruits, and dairy products in Beijing is dependent on the transportation of trucks at night. There are a large number of trucks driving in the city at night. The load capacity of the truck and its weight are larger than that of a car, so the power of the engine will be greater than that of the car at the same speed. This means that trucks will generate more emissions. Since not all trucks at night belong to Beijing, there can be some missing and errors in the data on truck emission control levels. The emission of these trucks is another problem worthy of further discussion. More detailed discussions will be conducted in our future studies.

\subsubsection{Estimation of Urban Road Pollution Concentration.} The road pollutant concentration detector was placed on the experimental road section of the Fourth Ring Road between the Jianxiang Bridge and Anhui Bridge, with a vertical height of about 5 meters from the ground. The linear distance from the Olympic Sports Center monitoring site to the detector is about 780 meters without the obstruction of tall buildings. The period measured by the detector is from August $7^{\text {th }}$ to August $12^{\text {th }}$. The red line in Figure 16 was the concentration of $\mathrm{PM}_{2.5}$ on the experimental road section. Combining meteorological data, traffic emission data, and foreign pollutant data at a corresponding time into the model, the estimated road can be calculated. The green line in Figure 16 was the concentration of $\mathrm{PM}_{2.5}$ at the Olympic Sports Center monitoring site. Part of the data at the Olympic Sports Center monitoring site is missing within this period. To ensure authenticity, the results are directly displayed and not filled here. The $\mathrm{PM}_{2.5}$ concentration value calculated by the model is the blue line in Figure 17.

From the red curve, five peaks of pollutant concentration can be found at $8 \mathrm{pm}$ on August $7^{\text {th }}$, from $3 \mathrm{am}$ to $6 \mathrm{am}$ on August 9th, at $3 \mathrm{pm}$ and $5 \mathrm{pm}$ on August $9^{\text {th }}$, and from $10 \mathrm{am}$ on August $10^{\text {th }}$ to 4 am on August $11^{\text {th }}$. At the first peak, from $6 \mathrm{pm}$ to $8 \mathrm{pm}$ on August $7^{\text {th }}$, the concentration of $\mathrm{PM}_{2.5}$ rose from $46 \mu \mathrm{g} / \mathrm{m}^{3}$ to $82 \mu \mathrm{g} / \mathrm{m}^{3}$, and fell to $41 \mu \mathrm{g} / \mathrm{m}^{3}$ at $10 \mathrm{pm}$.

When pollutants are input from the outside, the monitoring sites on the monitoring zones will appear ACP situation. The ascent rate is defined as the increase of pollutants within an hour, as a basis for judging whether there is an external input of pollutants. The ascent rate and descent rate of $\mathrm{PM}_{2.5}$ concentration are about $20 \mu \mathrm{g} / \mathrm{m}^{3}$ per hour. The rise time of $\mathrm{PM}_{2.5}$ concentration is also consistent with the night peak hours of the traffic in the studied Fourth Ring Road area. After the first concentration peak, the $\mathrm{PM}_{2.5}$ concentration continued to rise until the second concentration peak was higher than the first peak concentration value. From lam on August $8^{\text {th }}$ to noon on August $9^{\text {th }}$, the southwest wind continued to blow in the Beijing area. At 9am on August $8^{\text {th }}$, an external pollutant input in the southwest occurred. At 5 am on August $9^{\text {th }}$, the concentration of foreign $\mathrm{PM}_{2.5}$ reached a maximum of about $75 \mu \mathrm{g} / \mathrm{m}^{3}$. At $7 \mathrm{am}$, the maximum $\mathrm{PM}_{2.5}$ concentration on the road reaches about $144 \mu \mathrm{g} / \mathrm{m}^{3}$. The third peak occurred at $3 \mathrm{pm}$ on August $9^{\text {th }}$, with a $\mathrm{PM}_{2.5}$ concentration of $140 \mu \mathrm{g} / \mathrm{m}^{3}$. Compared with previous hour, the concentration increased by $30 \mu \mathrm{g} / \mathrm{m}^{3}$ and decreased by $80 \mu \mathrm{g} / \mathrm{m}^{3}$ in the next hour, and it is not the peak time of traffic emissions, so it can be concluded that this is due to the impact of external pollution. The fifth peak occurred at $11 \mathrm{am}$ on August 10, and $\mathrm{PM}_{2.5}$ concentration rose $30 \mu \mathrm{g} / \mathrm{m}^{3}$ within an hour. Since it is also a nontraffic peak, combined with weather information, it can be inferred that it is imported pollution from the southeast direction.

At 5 pm on August $9^{\text {th }}$, the $\mathrm{PM}_{2.5}$ concentration began to decrease rapidly and dropped to about $40 \mu \mathrm{g} / \mathrm{m}^{3}$ at $7 \mathrm{pm}$. During this time, the Fourth Ring Road is at the peak of night traffic, but the $\mathrm{PM}_{2.5}$ concentration is the point of decline. Combined with meteorological data, it was discovered that there was a heavy rain in Beijing at this time. It can be inferred that the rainfall process is also one of the important factors of $\mathrm{PM}_{2.5}$ concentration. The Olympic Sports Center monitoring site is about 780 meters away from the road monitoring site. The green line in Figure 16 is the pollutant concentration of the monitoring point of the Olympic Sports Center. It can be found that the general trend of the concentration of the detection site of the Olympic Sports Center is very close to that of the road monitoring site, and the value is about one-third of the concentration of road pollutants. We suspect that the diffusion of PM pollutants decreases with increasing distance, and similar conclusions can be obtained from the literature of other researchers [41]. We will discuss this in future research.

We use $R^{2}, M A D$, and MAPE to evaluate the goodness of fit of the model. $R^{2}$ is one of the basic measures of goodness of model fit. The value range is between 0 and 1 . The closer the value is to 1 , the smaller the difference between the estimated value of the dependent variable and the empirical value. MAD (mean absolute deviation), MAPE (mean absolute percentage error), and MFB (mean fractional bias) are the measures that are independent of the mean value. The calculation formula can be found in Table 7 . The blue line in Figure 17 is the result of the model calculation. It can be seen that the data calculated by the model are not very ideal when the $\mathrm{PM}_{2.5}$ concentration changes sharply, and the fitting is ideal when the weather is sunny. During heavy rains, the $\mathrm{PM}_{2.5}$ concentration dropped significantly, but the concentration value obtained by the model is not as obvious as the actual value. This shows that the impact of the model on the heavy rain may need further research. By statistical analysis of the estimated results, we can get that the value of the model statistic $R^{2}$ is 0.92 . The value of MAPE is $9.2483 \%$, which is an acceptable relative error. The value of MAD is 5.8147. The results of the model calculation can well reflect the concentration of pollutants on the road network.

The variables were grouped into meteorological conditions (temperature, wind direction, wind power, relative humidity, rainfall, and atmospheric pressure), traffic emission (when calculating traffic emissions, temporal conditions such as a different hour of the day, working days, and nonworking days are included in the calculation. Therefore, traffic emissions can be regarded as temporal conditions), and external pollution. The percentage contribution to the total sum of importance in a given model is shown in Figure 18 shows the distribution of $\mathrm{PM}_{2.5}$ concentration at 


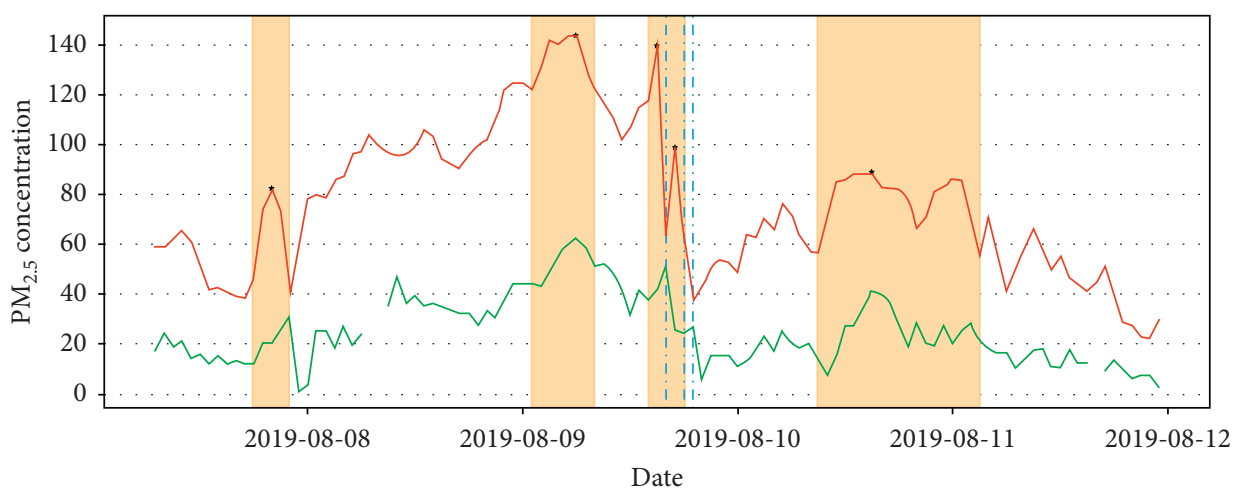

_ Experimental road monitoring site

— Olympic sports center monitoring site

FIGURE 16: Comparison between experimental monitoring site and Olympic Sports Center monitoring site.

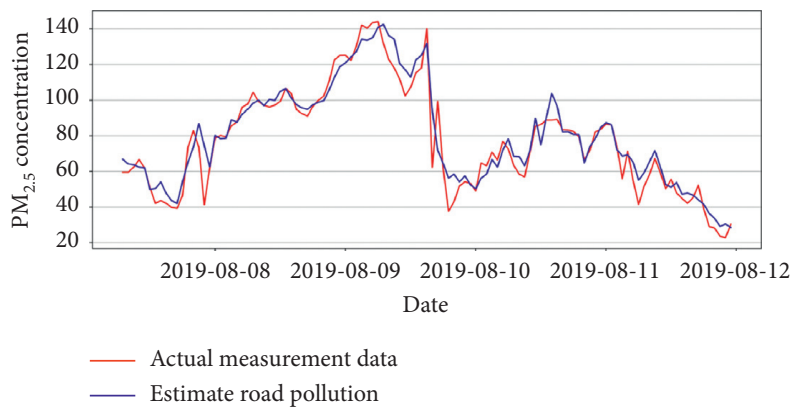

Figure 17: Comparison between experimental monitoring site and model output.

TABle 7: Goodness of fit.

\begin{tabular}{lc}
\hline & Equation \\
\hline$R^{2}$ & $R^{2}=1-\left(\left(\sum_{i=1}^{N}\left(y_{i}-\widehat{y}_{i}\right)^{2}\right) /\left(\sum_{i=1}^{N}\left(y_{i}-\bar{y}_{i}\right)^{2}\right)\right)$ \\
Mean absolute deviation & $\operatorname{MAD}=1 / N\left(\sum_{i=1}^{N}\left|\widehat{y}_{i}-y_{i}\right|\right)$ \\
Mean absolute percentage error & $\operatorname{MAPE}=1 / N\left(\sum_{i=1}^{N}\left|\widehat{y}_{i}-y_{i}\right| /\left|y_{i}\right|\right)$ \\
Mean fractional bias & $\operatorname{MFB}=1 / N\left(\sum_{i=1}^{N} \widehat{y}_{i}-y_{i} /\left(1 / 2\left(y_{i}+\widehat{y}_{i}\right)\right)\right)$ \\
\hline
\end{tabular}

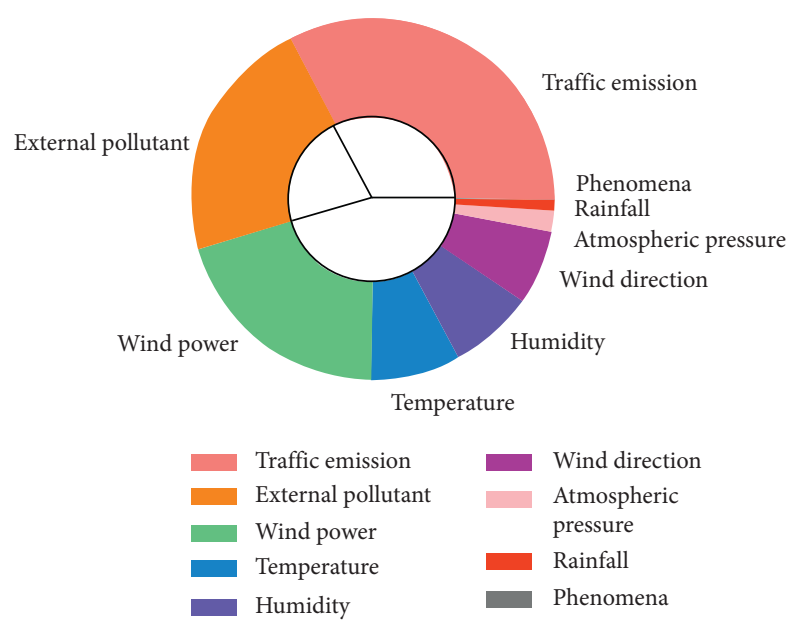

FIgURE 18: Feature importance for the variables. 
the monitoring point of the Olympic Sports Center at different time scales. The result shows that the $\mathrm{PM}_{2.5}$ pollutant value in winter months (December, January, and February) is higher than that in summer months (June, July, and August). Especially, in January, there was heavy pollution imported from other regions. By dividing the data according to the day of the week, it is found that the daily pollution situation is more average, but it is prone to abnormal heavy pollution on nonworking days. Looking at 24 hours of a day, the median pollutants in peak hours are slightly higher than those in evening peak hours, and there are also higher median pollutants in the early morning hours, which are higher than those in early peak hours.

The standardized regression coefficient of the model is shown in Table 8.

In August 2019, traffic emission is the most important factor affecting the concentration of $\mathrm{PM}_{2.5}$ on the road. The second influencing factor is pollution imported from other regions (external input pollution). Externally, $\mathrm{PM}_{2.5}$ will affect the pollutant concentration on the road significantly. Although meteorological data accounted for the largest proportion of the overall impact, it was not the largest among various factors.

In meteorological data, the effect of wind power is the most significant one. In the case of wind power above level 3, it is conducive to the spread of pollutants. Temperature and relative humidity also have a significant effect on the concentration of $\mathrm{PM}_{2.5}$. Heavy rain also has a very significant effect on the concentration of $\mathrm{PM}_{2.5}$, but the days of heavy rain in August are rare. The effect of heavy rain was not reflected in the proportion chart, but it is still a factor that cannot be ignored. This finding is following the analyses performed by other researchers [37, 42]. In Oslo, the most significant variable was the number of vehicles and the next most important variable for $\mathrm{PM}_{2.5}$ was the day number.

\subsection{Estimation of Pollutant Concentration on the Urban Road} Network. We apply the model to the entire urban road network in Beijing. The GPS data of vehicles were used to obtain traffic data such as travel speed and flow of different roads. The pollution concentration of the urban road network in August is shown in Figure 19.

At the time of the morning peaks, there are three road sections with $\mathrm{PM}_{2.5}$ concentrations over $80 \mu \mathrm{g} / \mathrm{m}^{3}$ throughout the Second Ring Road, which is located between Andingmen and Xizhimen on the North Second Ring Road, from the Caihuying Bridge to Fuxingmen Bridge on the West Second Ring Road, and in the road section between the Zuo'anmen Bridge and the Jianguomen Bridge on the East Second Ring Road.

In the Third Ring Road, the concentration of pollutants in the road from the Lotus Bridge to the Lize Bridge in the West Third Ring Road and the road from Fenzhong Temple Bridge to the Guomao in the East Third Ring Road exceeded 80 $\mu \mathrm{g} / \mathrm{m}^{3}$. The sections from the Fengbei Bridge on the West Fourth Ring Road to the Nanshawo Bridge, the Sifang Bridge on the East Fourth Ring Road to the Dajiaoting Bridge, and the Jianxiang Bridge to the Wanghe Bridge all exceeded $80 \mu \mathrm{g} / \mathrm{m}^{3}$.
TABLE 8: Standardized regression coefficient of the model.

\begin{tabular}{lc}
\hline Feature & Standardized regression coefficient \\
\hline Traffic emission & 0.6361 \\
External pollutant & 0.4293 \\
Wind power & 0.3988 \\
Temperature & 0.1547 \\
Relative humidity & -0.1516 \\
Wind direction & 0.1263 \\
Atmospheric pressure & 0.0352 \\
Rainfall & -0.0191 \\
Phenomena & -0.0037 \\
\hline
\end{tabular}

The concentration of $\mathrm{PM}_{2.5}$ at the Shangqing Bridge on the Fifth Ring Road also exceeded $80 \mu \mathrm{g} / \mathrm{m}^{3}$. The section from the Sun Palace Bridge to the Laiguangying Bridge is the same, where the pollutant concentration exceeds $80 \mu \mathrm{g} / \mathrm{m}^{3}$. This may be because these road sections are very congested during the morning peak period. According to the distribution of road sections with high pollution concentration, we can find that the increasing trend of peak road pollution concentration is the north, northeast, southwest, and southeast directions, spreading from the outside to the inside of the urban area. This is roughly consistent with people's commuting patterns.

The spatiotemporal change process of the $\mathrm{PM}_{2.5}$ concentration of the road network during the morning peak period is shown in Figure 20. We found that the spread of $\mathrm{PM}_{2.5}$ concentration in the urban road network is positively correlated with urban commuting. In some commuter-intensive roads and some key intersections, the concentration of $\mathrm{PM}_{2.5}$ exceeds other roads. For instance, the enlarged part in Figure 20 contains our experimental section in the previous part (the road between the Jianxiang Bridge and Anhui Bridge). At 9 am, this road reached the highest concentration, and the concentration of $\mathrm{PM}_{2.5}$ during the morning peak hour was higher than most of the road sections connected. This section can be considered as a polluted section during the morning peak period and needs to be given more attention. Environmental protection agencies can conduct more monitoring on such road sections. And some methods can be used to purify the air or absorb pollution to reduce the pollution level during the morning peak period of the road section to ensure the health of people living and working near the road section.

From the temporal and spatial changes of the entire road network, we can deduce that in the northern suburbs of the central city, Xizhimen and Zhongguancun are the main destinations for commuting. Therefore, during the morning rush hour on working days, it can be observed that the concentration of $\mathrm{PM}_{2.5}$ on the road spreads from the south to the north on the Badaling Expressway, and from the east to the west on the North Fourth Ring Road. Eventually, the maximum concentration of road pollutants appears close to Xizhimen and Zhongguancun. In the northeast area of the central urban, there are large communities such as Tiantongyuan. Therefore, the concentration of road pollutants spreads along the main route into the central urban, from the Guangying Bridge to the Taiyanggong Bridge, then towards 


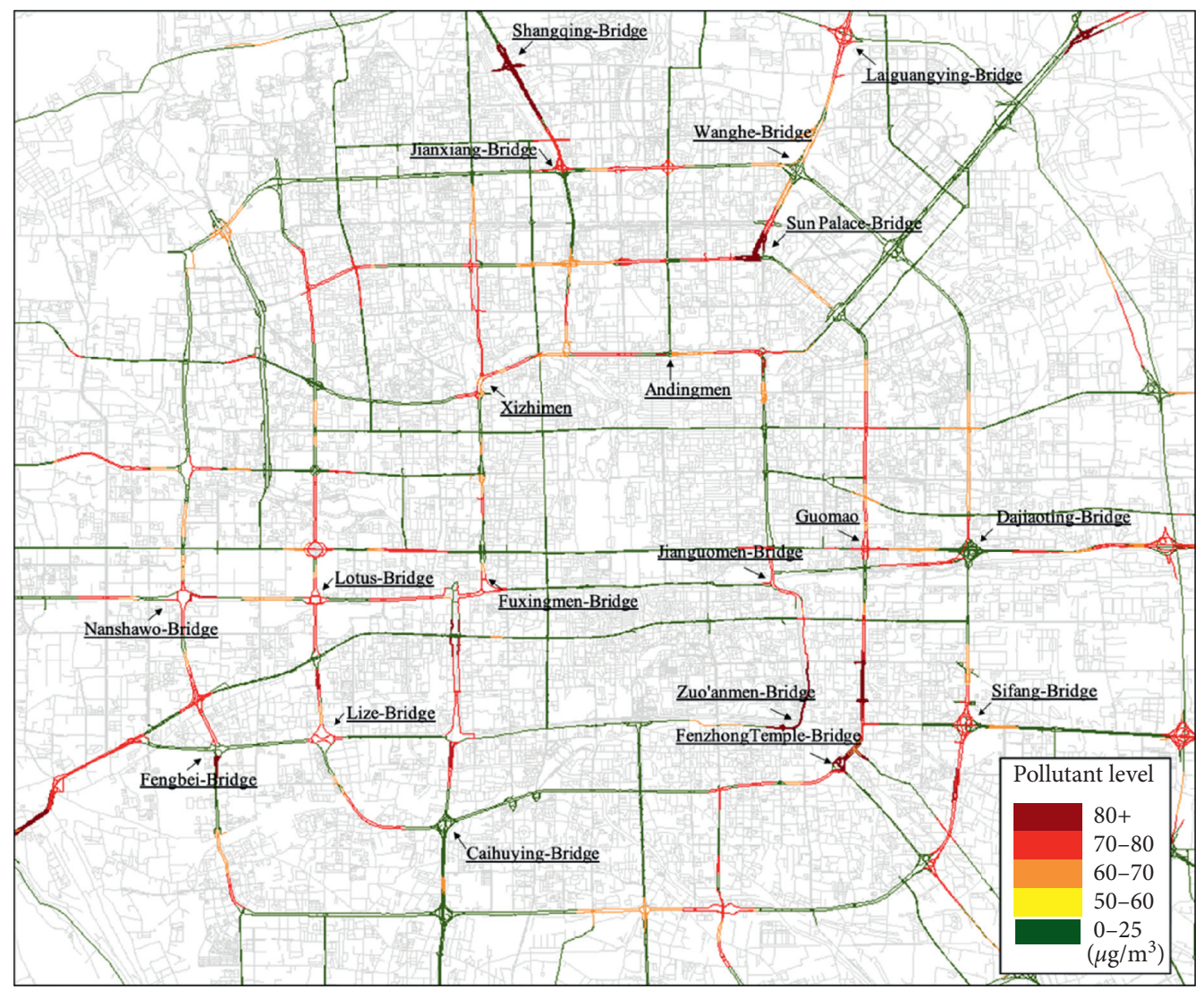

Figure 19: $\mathrm{PM}_{2.5}$ concentration of the urban road network at $7 \mathrm{am}$ in August.

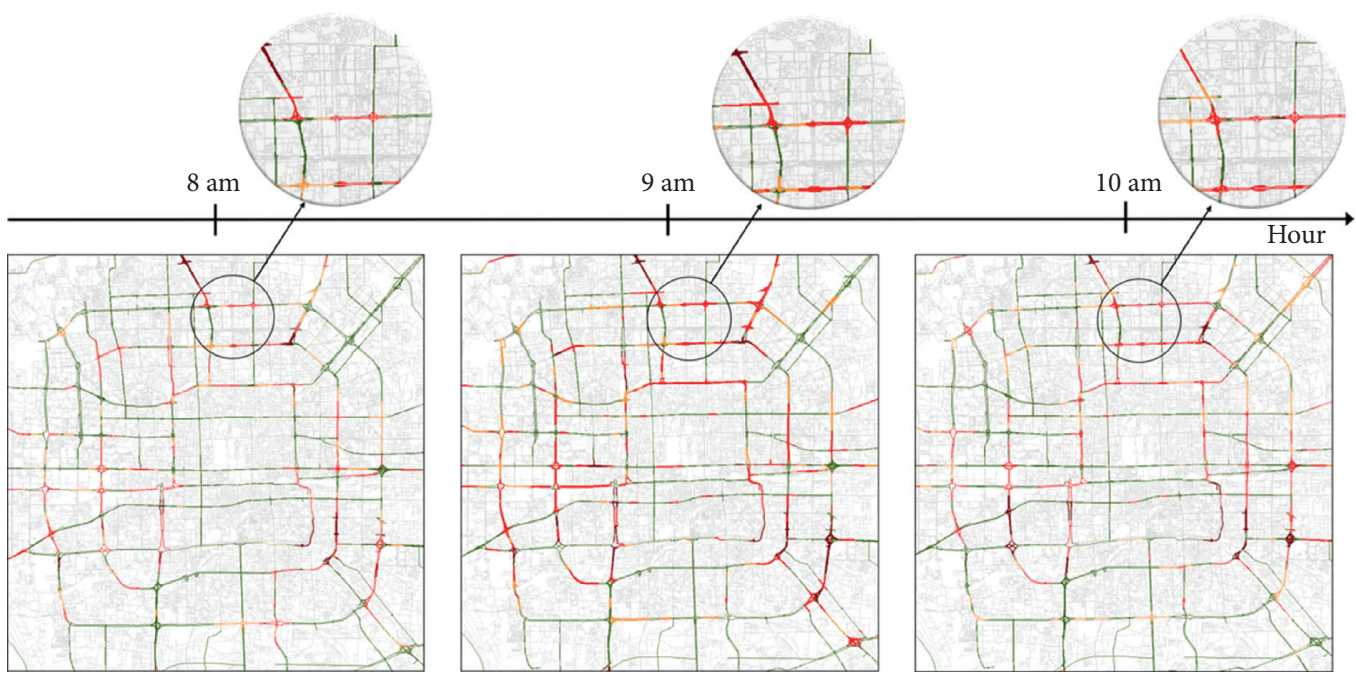

FIgURE 20: The pollutant concentration of the road network at 7am, 8am and 9am the peak of Beijing.

Zhongguancun and Xizhimen. There is also pollutant dispersion to the direction of Guomao. Tongzhou District, Beijing's administrative subcenter, is located in the east of the central urban. Therefore, at the morning rush hour, the road pollution concentration between the Beijing-Tongtong expressways is high, and the concentration of the pollutants is transmitted from Tongzhou to the direction of Guomao. In the southwest of the central urban, the concentration of road pollutants also spreads from outside to the central urban areas.

Because most of the data used in this study are based on hourly observations, the accuracy of this study could be limited. If data at the monitoring sites in minutes can be obtained, the estimated pollutant propagation process can be described in more detail. More detailed meteorological data and traffic data are also helpful to improve the accuracy of 
urban road network pollutant concentration estimation. It should also be noted that the establishment of more monitoring equipment placed on urban road networks can be conducive to improving the reliability of the monitoring system. Therefore, in future studies, it is necessary to introduce monitoring data placed on urban road networks. Besides, the advancement of electric vehicle technology and the popularization of charging facilities in cities will increase the use of electric vehicles in cities, bringing changes in the composition of mobility tools, which consequently influences emission and pollutant concentration as a whole.

\section{Conclusions}

Since most of the monitoring sites are far away from the arterial road, the concentration of $\mathrm{PM}_{2.5}$ at the city monitoring sites cannot reflect the pollution situation near roads, and the value of pollutant concentration may be underestimated. The $\mathrm{PM}_{2.5}$ concentration on the road maybe 2-5 times that of urban monitoring sites.

It can be seen from the estimated results of the $\mathrm{PM}_{2.5}$ concentration of the road network that there are some heavily polluted road sections within the Fourth Ring Road, such as Xizhimen, Guomao, and Deshengmen. The $\mathrm{PM}_{2.5}$ concentration at these critical road sections exceeds $70 \mu \mathrm{g} / \mathrm{m}^{3}$. In the north of the central city, the $\mathrm{PM}_{2.5}$ concentration on the road spreads through the Jianxiang Bridge and Sun Palace Bridge to Xizhimen, in the southeast of the central city, from Tongzhou to Zuoanmen and Guomao, and in the southwest of the central city, from Fangshan to Fuxingmen and the Lotus Bridge. This can be found from the comparison of the temporal and spatial distribution of road pollution concentration and the relative distribution of traffic congestion.

The multivariate linear model shows that not only is the $\mathrm{PM}_{2.5}$ concentration on urban road networks due to vehicle emissions, but also $\mathrm{PM}_{2.5}$ in the background environment and meteorological conditions play an important role. Meteorologically, factors such as wind power, relative humidity, and temperature have a nonnegligible effect on pollutant concentration. Heavy rain may cause a significant drop in $\mathrm{PM}_{2.5}$ concentration. It will be discussed further in future research.

In this study, a method is established to estimate $\mathrm{PM}_{2.5}$ concentration of road network based on traffic status. The model proposed in this study describes the spatial and temporal distribution of traffic pollutants to a certain extent and analyzed the relationship between traffic status, vehicle emissions, input pollutant concentration, and the impact of meteorology on pollutant concentration. This method may have a contribution in the future when establishing an urban air quality pollutant or health assessment framework. It will be discussed further in future research.

\section{Appendix}

\section{Experimental Monitoring Site}

The 16 administrative districts of Beijing are Dongcheng District, Xicheng District, Chaoyang District, Fengtai
District, Shijingshan District, Haidian District, Shunyi District, Tongzhou District, Daxing District, Fangshan District, Mentougou District, Changping District, Pinggu District, Miyun District, Huairou District, and Yanqing District.

The vehicle GPS data used in this study come from our long-term collection and some data from the Beijing $\mathrm{Mu}$ nicipal Transportation Administration.

The mathematical formulae for these coefficients of the goodness of fit are given in Table 7 , where $\hat{y}_{i}$ is the $i^{\text {th }}$ theoretical value (from the model), $y_{i}$ is the $i^{\text {th }}$ empirical (real) value, $\bar{y}_{i}$ is the mean empirical value, and $\mathrm{N}$ is the sample size.

\section{Data Availability}

The data used to support the findings of this study are available from the corresponding author upon request.

\section{Conflicts of Interest}

The authors declare that they have no conflicts of interest.

\section{Acknowledgments}

This research was supported by the National Natural Science Foundation of China (U1811463).

\section{References}

[1] M. Adam, T. Schikowski, A. E. Carsin et al., "Adult lung function and long-term air pollution exposure. ESCAPE: a multicentre cohort study and meta-analysis," European Respiratory Journal, vol. 45, no. 1, pp. 38-50, 2015.

[2] G. Villani, R. M. Krishnan, R. Beelen et al., "Long-term air pollution exposure and cardio-respiratory mortality: a review," Environmental Health: A Global Access Science Source, vol. 12, no. 1, 2013.

[3] F. J. Kelly and J. C. Fussell, "Air pollution and airway disease," Clinical \& Experimental Allergy, vol. 41, no. 8, pp. 1059-1071, 2011.

[4] D. Phung, T. T. Hien, H. N. Linh et al., "Air pollution and risk of respiratory and cardiovascular hospitalizations in the most populous city in Vietnam," Science of the Total Environment, vol. 557-558, pp. 322-330, 2016.

[5] M.-C. Flores-Pajot, M. Ofner, M. T. Do, E. Lavigne, and P. J. Villeneuve, "Childhood autism spectrum disorders and exposure to nitrogen dioxide, and particulate matter air pollution: a review and meta-analysis," Environmental Research, vol. 151, pp. 763-776, 2016.

[6] WHO, Burden of Disease from Ambient Air Pollution for 2012, World Health Organization, Geneva, Switzerland, Lmi, 2012-2014, 2014.

[7] Beijing Transportation Research Center, Beijing Transport Annual Report, Beijing Transportation Research Centre, Beijing, China, 2019.

[8] Health Effects Institute, "A critical review of the literature on emissions, exposure and health effects. HEI special report 17.17," in Traffic-Related Air PollutionHealth Effects Institute, Boston, MA, USA, 2010.

[9] D. Sun and X. Ding, "Spatiotemporal evolution of ride sourcing markets under the new restriction policy: a case 
study in Shanghai," Transportation Research Part A: Policy and Practice, vol. 130, pp. 227-239, 2019.

[10] Q. Zhang, J. Xu, G. Wang, W. Tian, and H. Jiang, "Vehicle emission inventories projection based on dynamic emission factors: a case study of Hangzhou, China," Atmospheric Environment, vol. 42, no. 20, pp. 4989-5002, 2008.

[11] Z. Wang, Y. Wu, Y. Zhou et al., "Real-world emissions of gasoline passenger cars in Macao and their correlation with driving conditions," International Journal of Environmental Science and Technology, vol. 11, no. 4, pp. 11351146, 2014.

[12] M. Lee, M. Brauer, P. Wong et al., "Land use regression modelling of air pollution in high density high rise cities: a case study in Hong Kong," Science of the Total Environment, vol. 592, pp. 306-315, 2017.

[13] S. Yang, H. Wu, J. Chen, X. Lin, and T. Lu, "Optimization of PM2.5 estimation using landscape pattern information and land use regression model in Zhejiang, China," Atmosphere, vol. 9, no. 2, p. 47, 2018.

[14] J. Gulliver, D. Morley, C. Dunster et al., "Land use regression models for the oxidative potential of fine particles (PM 2.5) in five European areas," Environmental Research, vol. 160, pp. 247-255, 2018.

[15] E. Hoek, R. Vermeulen, M.-Y. Tsai et al., "Land use regression models for ultrafine particles in six European areas," Environmental Science \& Technology, vol. 51, no. 6, pp. 3336-3345, 2017.

[16] S. Vlaanderen and J. D. Marshall, "Land use regression models of on-road particulate air pollution (particle number, black carbon, PM2.5, particle size) using mobile monitoring," Environmental Science \& Technology, vol. 49, no. 15, pp. 9194-9202, 2015.

[17] S. Weichenthal, K. Van Ryswyk, A. Goldstein, M. Shekarrizfard, and M. Hatzopoulou, "Characterizing the spatial distribution of ambient ultrafine particles in Toronto, Canada: a land use regression model," Environmental Pollution, vol. 208, pp. 241-248, 2016.

[18] L. Zhai, B. Zou, X. Fang, Y. Luo, N. Wan, and S. Li, "Land use regression modeling of PM2.5 concentrations at optimized spatial scales," Atmosphere, vol. 8, no. 1, p. 1, 2016.

[19] L.-J. S. Liu, I. Curjuric, D. Keidel et al., "Characterization of source-specific air pollution exposure for a large population-based Swiss cohort (SAPALDIA)," Environmental Health Perspectives, vol. 115, no. 11, pp. 1638-1645, 2007.

[20] B. Barratt, R. Atkinson, H. Ross Anderson et al., "Investigation into the use of the CUSUM technique in identifying changes in mean air pollution levels following introduction of a traffic management scheme," Atmospheric Environment, vol. 41, no. 8, pp. 1784-1791, 2007.

[21] Beijing Municipal Bureau of Statistics, Beijing Statistical Yearbook, China Statistics Press, Beijing, China, 2019.

[22] F. Chen, Z. Yin, Y. Ye, and D. Sun, "Taxi hailing choice behavior and economic benefit analysis of emission reduction based on multi-mode travel big data," Transport Policy, vol. 97, pp. 73-84, 2020.

[23] A. Sayegh, J. E. Tate, and K. Ropkins, "Understanding how roadside concentrations of NOx are influenced by the background levels, traffic density, and meteorological conditions using boosted regression trees," Atmospheric Environment, vol. 127, pp. 163-175, 2016.

[24] D. Sun, K. Zhang, and S. Shen, "Analyzing spatiotemporal traffic line source emissions based on massive didi online car-hailing service data," Transportation Research Part D: Transport and Environment, vol. 62, no. 800, pp. 699-714, 2018.
[25] K. Zhang and S. Batterman, "Air pollution and health risks due to vehicle traffic," Science of the Total Environment, vol. 450-451, pp. 307-316, 2013.

[26] R. H. Keeler, "A machine learning model of Manhattan air pollution at high spatial resolution," MIT thesis, Massachusetts Institute of Technology, Cambridge, MA, USA, 2014.

[27] P. Mlakar and M. Boznar, "Analysis of winds and $\mathrm{SO} 2$ concentrations in complex terrain," in AIR POLLUTION IV: MONITORING, SIMULATION AND CONTROL, B. Caussade, H. Power, and C.A Brebbia, Eds., pp. 455-464, 1969.

[28] J. Fan, K. Gao, Y. Xing, and J. Lu, "Evaluating the effects of one-way traffic management on different vehicle exhaust emissions using an integrated approach," Journal of Advanced Transportation, vol. 2019, Article ID 6248796, 11 pages, 2019.

[29] I. González-Aparicio, J. Hidalgo, A. Baklanov, A. Padró, and O. Santa-Coloma, "An hourly PM10 diagnosis model for the Bilbao metropolitan area using a linear regression methodology," Environmental Science and Pollution Research, vol. 20, no. 7, pp. 4469-4483, 2013.

[30] E. Goswami, T. Larson, T. Lumley, and L.-J. S. Liu, "Spatial characteristics of fine particulate matter: identifying representative monitoring locations in Seattle, Washington," Journal of the Air \& Waste Management Association, vol. 52, no. 3, pp. 324-333, 2002.

[31] L. T. Padró-Martínez, A. P. Patton, J. B. Trull, W. Zamore, D. Brugge, and J. L. Durant, "Mobile monitoring of particle number concentration and other traffic-related air pollutants in a near-highway neighborhood over the course of a year," Atmospheric Environment, vol. 61, pp. 253-264, 2012.

[32] D. Sun (Jian), Y. Zhang, R. Xue, and Y. Zhang, "Modeling carbon emissions from urban traffic system using mobile monitoring," Science of the Total Environment, vol. 599-600, pp. 944-951, 2017.

[33] J. A. Kamińska, "The use of random forests in modelling short-term air pollution effects based on traffic and meteorological conditions: a case study in Wrocław," Journal of Environmental Management, vol. 217, pp. 164-174, 2018.

[34] K. S. Chan, W. H. K. Lam, and M. L. Tam, "Real-time estimation of arterial travel times with spatial travel time covariance relationships," Transportation Research Record, vol. 2121, pp. 102-109, 2009.

[35] X. Yang, H. Liu, and K. He, "The significant impacts on traffic and emissions of ferrying children to school in Beijing," Transportation Research Part D: Transport and Environment, vol. 47, pp. 265-275, 2016.

[36] T. Hastie, R. Tibshirani, and J. Friedman, "Springer series in statistics," in The Elements of Statistical LearningSpringer, Berlin. Germany, 2009.

[37] I. Laña, J. Del Ser, A. Padró, M. Vélez, and C. CasanovaMateo, "The role of local urban traffic and meteorological conditions in air pollution: a data-based case study in Madrid, Spain," Atmospheric Environment, vol. 145, pp. 424-438, 2016.

[38] D. Westerdahl, S. Fruin, T. Sax, P. M. Fine, and C. Sioutas, "Mobile platform measurements of ultrafine particles and associated pollutant concentrations on freeways and residential streets in Los Angeles," Atmospheric Environment, vol. 39, no. 20, pp. 3597-3610, 2005.

[39] S. Fruin, D. Westerdahl, T. Sax, C. Sioutas, and P. M. Fine, "Measurements and predictors of on-road ultrafine particle concentrations and associated pollutants in Los Angeles," Atmospheric Environment, vol. 42, no. 2, pp. 207-219, 2008.

[40] GB3095-2012, Ambient Air Quality Standards, in Chinese. 
[41] J. M. Wang, C.-H. Jeong, N. Hilker et al., "Near-road air pollutant measurements: accounting for inter-site variability using emission factors," Environmental Science \& Technology, vol. 52, no. 16, pp. 9495-9504, 2018.

[42] Z. Zhang, X. Zhang, D. Gong et al., "Evolution of surface $\mathrm{O}_{3}$ and $\mathrm{PM}_{2.5}$ concentrations and their relationships with meteorological conditions over the last decade in Beijing," Atmospheric Environment, vol. 108, pp. 67-75, 2015. 